\title{
HRTEM/AEM AND SEM STUdY OF FLUID-RoCk INTERACTIONS: INTERACTION OF COPPER, SILVER, Selenium, Chromium, and Cadmium-Bearing Solutions With Geological MATERIALS AT NEAR SurfaCe CONDITIONS, WITH AN EMPHASIS ON Phyllosilicates
}

\author{
Progress Report \\ September 15, 1991 - September 14, 1992 \\ David R. Veblen and Eugene S. Ilton \\ Department of Earth and Planetary Sciences \\ The Johns Hopkins University \\ Baltimore, Maryland 21218
}

May, 1992

Prepared for the U. S. Department of Energy

Agreement No. DE-FG02-89ER 14074

\section{NOTICE}

This report was prepared as an account of work sponsored by the United States Government. Neither the United States nor the Department of Energy, nor any of their contractors, subcontractors, or their employees, makes any warranty, express or implied, or assumes any legal liability or responsibility for the accuracy, completeness, or usefulness of any information, apparatus, product, or process disclosed or represents that its use would not infringe privately owned rights. 


\section{DISCLAIMER}

This report was prepared as an account of work sponsored by an agency of the United States Government. Neither the United States Government nor any agency Thereof, nor any of their employees, makes any warranty, express or implied, or assumes any legal liability or responsibility for the accuracy, completeness, or usefulness of any information, apparatus, product, or process disclosed, or represents that its use would not infringe privately owned rights. Reference herein to any specific commercial product, process, or service by trade name, trademark, manufacturer, or otherwise does not necessarily constitute or imply its endorsement, recommendation, or favoring by the United States Government or any agency thereof. The views and opinions of authors expressed herein do not necessarily state or reflect those of the United States Government or any agency thereof. 


\section{DISCLAIMER}

Portions of this document may be illegible in electronic image products. Images are produced from the best available original document. 


\section{TABLE OF CONTENTS}

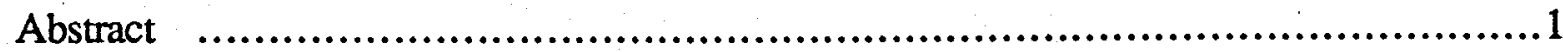

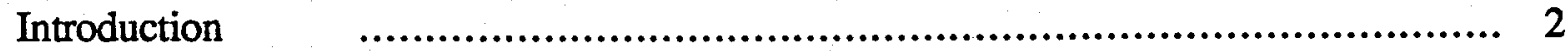

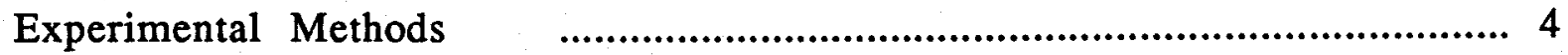

Transmission Electron Microscopy (TEM) ......................................... 4

Scanning Electron Microscopy (SEM) …........................................ 4

Electron Microprobe Analysis (EMP) $\quad$................................................. 4

X-ray Photoelectron Spectroscopy (XPS) $\quad$............................................... 4

Fluid Analysis $\quad$......................................................................... 5

TEM, SEM, EMP, and XPS Sample Preparation $\quad$.................................... 5

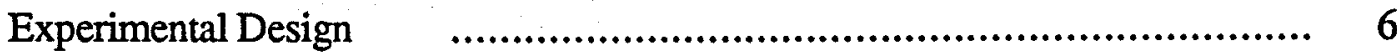

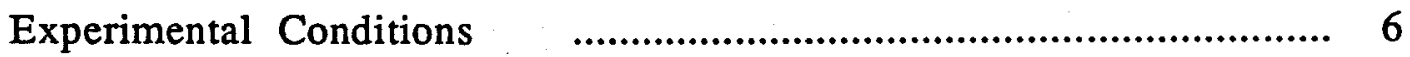

Research Progress

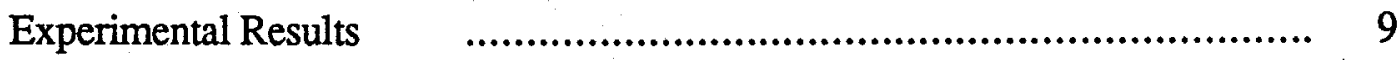

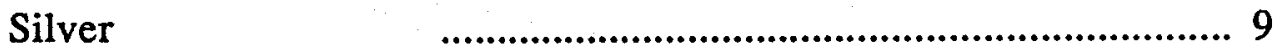

Selenium

Chromium

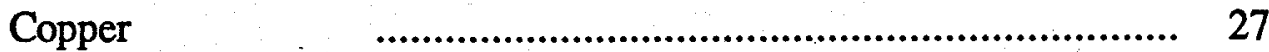

Copper-enriched Feldspars and Biotites from the Cyprus Casa Grande

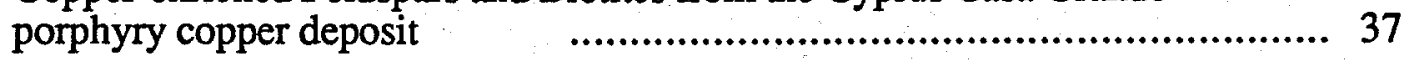

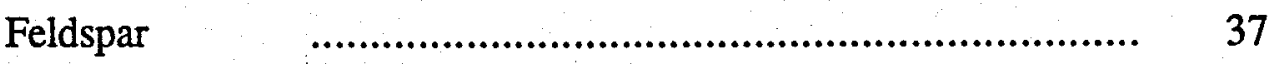

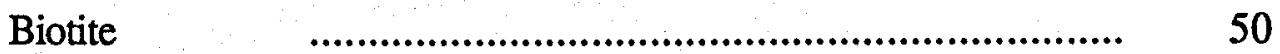

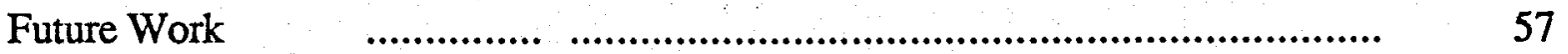

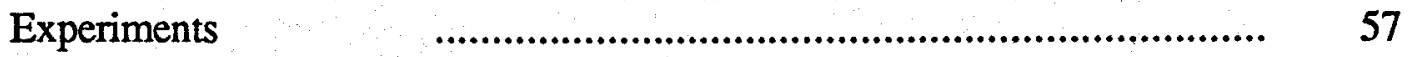

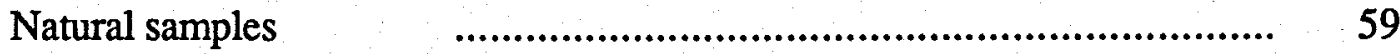

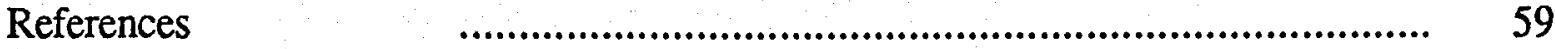

Appendix I: List of relevant publications for 1991-1992 _.................................. 61 


\section{LIST OF TABLES}

Table 1. Experimental set up.................................................................... 7

Table 2. Results from XPS analysis.............................................................26

Table 3. Representative electron microprobe... ................................................... 40

Table 4. Representative electron microprobe... ..................................................41

Table 5. Representative analytical electron microscope... ..........................................47

\section{LIST OF FIGURES}

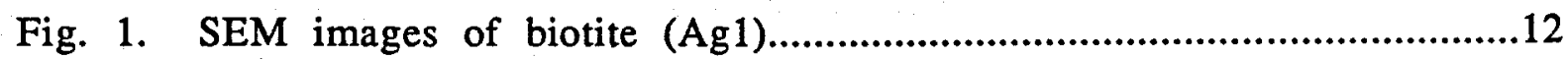

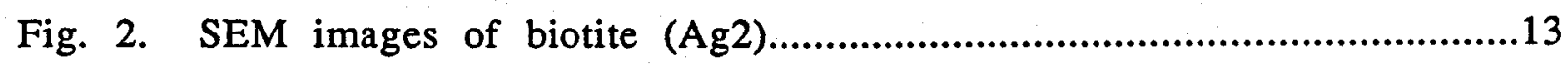

Fig. 3. EDS analyses of biotite (Ag2) ............................................................

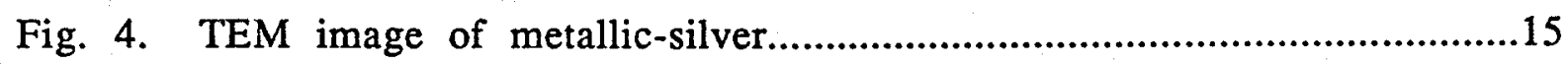

Fig. 5. TEM image of metallic-silver............................................................16

Fig. 6. A general XPS spectrum of biotite (Se1) surface.............................................18

Fig. 7. XPS spectrum of biotite (Se1) surface.........................................................19

Fig. 8. XPS spectra of an unreacted biotite surface and..............................................20

Fig. 9. EDS analysis of the edge of a biotite flake (Cr1-1) ..............................23

Fig.10. SEM images of the surface of a biotite flake (Cr1-1) ..............................24

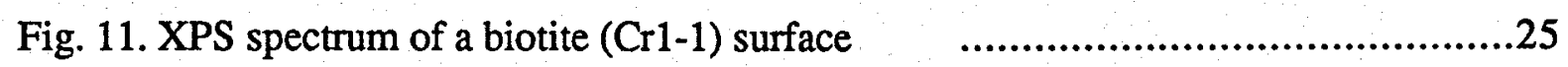

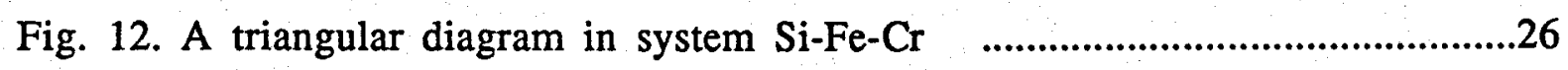

Fig. 13. Concentration of $\mathrm{Cu}$ in low-F biotite

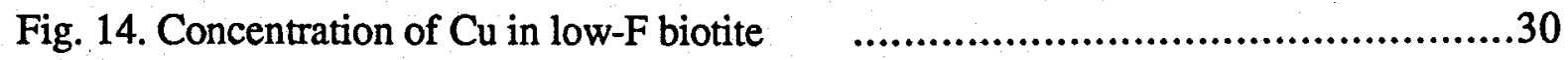

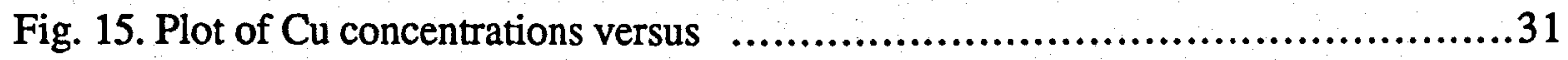

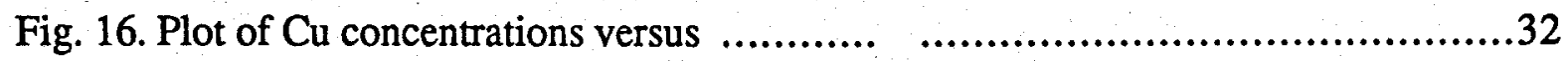

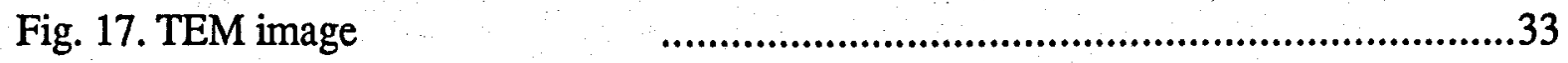

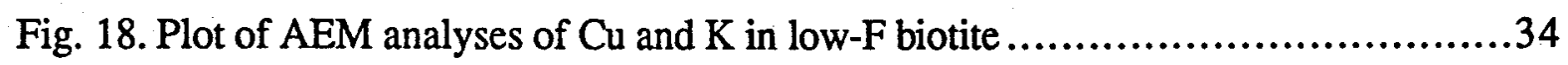

Fig. 19. Plot of Si concentrations versus

Fig. 20. Plot of Si concentrations versus 
Fig. 21. Low-magnification bright-field TEM image

Fig. 22. High-magnification bright-field TEM image ....................................... 43

Fig. 23. Selected-area electron diffraction $\quad$................................................... 44

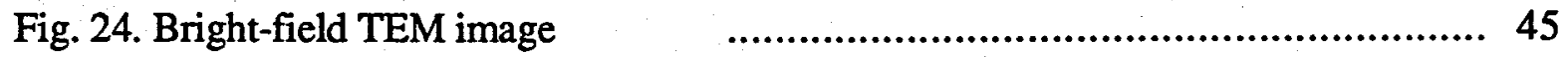

Fig. 25. High-resolution TEM image $\quad$.........................................................46

Fig. 26. Bright-field TEM image $\quad$ _....................................................... 48

Fig. 27. SEM backscatter electron photomicrograph of biotite.................................... 53

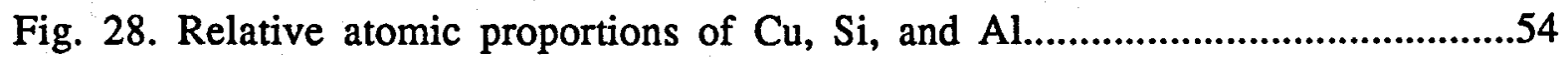

Fig. 29. HRTEM image of biotite $\quad$.............................................................. 55

Fig. 30. TEM image of biotite

\section{DISCLAIMER}

This report was prepared as an account of work sponsored by an agency of the United States Government. Neither the United States Government nor any agency thereof, nor any of their employees, makes any warranty, express or implied, or assumes any legal liability or responsibility for the accuracy, completeness, or usefulness of any information, apparatus, product, or process disclosed, or represents that its use would not infringe privately owned rights. Reference herein to any specific commercial product, process, or service by trade name, trademark, manufacturer, or otherwise does not necessarily constitute or imply its endorsement, recommendation, or favoring by the United States Government or any agency thereof. The views and opinions of authors expressed herein do not necessarily state or reflect those of the United States Government or any agency thereof. 


\section{ABSTRACT}

Biotite has been reacted with acidic solutions, at $25^{\circ} \pm 3^{\circ} \mathrm{C}$, bearing silver $\left(\mathrm{Ag}_{2} \mathrm{SO}_{4}\right)$, selenium (selenite), chromium (hexavalent $\mathrm{Cr}$ ), and copper $\left(\mathrm{CuSO}_{4}\right)$. The experiments were open to the atmosphere. Transmission electron microscopy (TEM) and scanning electron microscopy (SEM) show that biotite sorbs and reduces $\mathrm{Ag}^{+}(\mathrm{aq})$ to metallic silver. Polygonal precipitates and inclusions of metallic silver (with diameters ranging from 10's of angstroms to $\geq 1 \mu \mathrm{m}$ ) are concentrated on the edges of the biotite flakes and also in the interlayer region. This style of silver incorporation in the interlayer region is identical to that of copper (Ilton et al., in press).

X-ray photoelectron spectroscopy (XPS) of biotites reacted with selenite-bearing solutions show that the oxidation state of selenium sorbed on the surface of biotite is $\mathrm{Se}^{4+}$. XPS, therefore, does not provide evidence for reduction of selenium on the surface of biotite under the robust oxidizing conditions of the experiments and extraction procedure. SEM observations indicate that sorbed selenium is concentrated on edge sites and on an aluminosilicate phase that dots the surface of biotite. TEM observations of biotite edges show that $\mathrm{Se}$ is not associated with inclusions; these results suggest that selenium is either adsorbed to the biotite surface or incorporated into the biotite structure.

XPS of biotites reacted with $\mathrm{Cr}^{6+}$-bearing solutions show that the oxidation state of chromium sorbed on the surface of biotite is $\mathrm{Cr}^{3+}$. The XPS results are consistent with a model for sorption and reduction of chromium on the surface of biotite. Angle-resolved XPS shows that chromium is indeed concentrated at the biotite surface and that the sorbed chromium specie is probably $\mathrm{Cr}$-rich (as opposed to Fe-rich). SEM observations indicate that chromium is associated with edge sites and small biotite flakes that lie on the surface of the larger biotite grains. Thusfar, we have not found a separate Cr-rich phase.

Copper-bearing solutions were reacted with low-F biotite in contrast to our previous work with high-F biotite (Ilton et al., in press). Results indicate that low-F biotite absorbs 
more readily and extensively than high-F biotite. TEM observations show that copper is present as native copper inclusions in the interlayer region of biotite (as in the high-F biotites). Unlike the high-F biotites, however, appreciable copper is also incorporated into expanded interlayers. Moreover, the native copper inclusions are bigger and are present in denser arrays in low-F relative to high- $\mathrm{F}$ biotites.

Continued work on natural samples from the Cyprus Casa Grande porphyry copper deposit shows that weathered alteration products of feldspars from the chrysocolla zone have concentrated copper. Surprisingly, the copper appears as submicroscopic native copper precipitates. Such a finding indicates that native copper is more ubiquitous than previously thought.

Further work on copper-enriched biotite from the chrysocolla zone has revealed that the mode of copper incorporation in biotite is more complex than previously described. Among the more interesting findings, we have discovered, although not identified, a new form of copper in biotite: copper-rich inclusions that evaporate under the condensed electron beam. We assume that the inclusions are either a hydrated or carbonate copper phase.

\section{INTRODUCTION}

Oxidation-reduction reactions at the mineral-fluid interface can be responsible for the attenuation or mobilization of both toxic and non-toxic elements, and ore-forming elements in the near surface environment (e.g., see reviews by Hering and Stumm, 1990; White, 1990; and Bancroft and Hyland, 1990). In this study we have chosen to study the interaction of silver-, copper-, selenium ( $\mathrm{Se}^{4+}$ and $\left.\mathrm{Se}^{6+}\right)$-, and chromium $\left(\mathrm{Cr}^{6+}\right)$ - bearing solutions with ferrous silicates such as biotite, a potential reducing agent. Reduced forms of selenium and chromium are less soluble, and hence less mobile than oxidized forms. Moreover, trivalent chromium is less toxic than hexavalent chromium. Biotite containing ferrous iron was chosen 
for initial study because it is an ubiquitous, potential reducing agent in rocks and soils; ferrous iron in biotite can be a stronger reducing agent than $\mathrm{Fe}^{2+}(\mathrm{aq})$ (White and Yee, 1985).

The present study was motivated, in part, by the work of Ilton and Veblen (1988), Ilton et al. (in press) and Ilton and Veblen (in review), which was supported by DOE contract DE -FGO2-89ER14074 and reported by Veblen and Ilton in the 1991 DOE progress report. These earlier studies used transmission electron microscopy to demonstrate that biotite could absorb and reduce $\mathrm{Cu}^{2+}(\mathrm{aq})$ to native copper.

The emphasis of the reconnaissance experiments reported in this Progress Report was to examine the surfaces and interior portions of the reacted biotites with transmission electron microscopy (TEM), scanning electron microscopy (SEM), and X-ray photoelectron spectroscopy (XPS). XPS is a new technique for us; originally we did not plan to use it, however, Lehigh University has one of the most advanced XPS facilities in the world and it has proven to be a powerful tool for obtaining surface compositions and oxidations states of sorbed species on the surfaces of the reacted biotites from our experiments.

The primary goal of the copper experiments was to compare copper sorption in low-F biotites (this study) with copper sorption in high-F biotite (Ilton and Veblen, in press). Fluorine stabilizes potassium in biotite (Hoda and Hood, 1972); fluorine in biotite should, therefore, strongly effect the rate and amount of copper absorption by biotite.

We also report further work on copper-enriched biotites from the Cyprus Casa Grande porphyry copper. Moreover, we have extended our studies of naturally occurring copperenriched silicates to plagioclase and its alteration products.

The PI is and has been devoting 1/12 of his effort to this project. The Co-PI is, of course, devoting $12 / 12$ of his effort towards this project. 


\section{EXPERIMENTAL METHODS}

Transmission electron microscopy (TEM)- The TEM/AEM facilities at Johns Hopkins University have been described in detail in Itton el al. (in press), Iton and Veblen (in review), and Veblen and Iton (DOE progress reports for 1990 and 1991). In addition we have used the TEM/AEM facilities at Lehigh University (Philips 430T/ST and 400T). The operation of these electron microscopes is similar to the Philips 420T/ST at Johns Hopkins University. The Philips 430T/ST operates at an accelerating voltage of $250 \mathrm{keV}$, which provides greater depth penetration (i.e., one can image thicker specimens) than the Philips 420T/ST and 400T.

Scanning Electron Microscopy (SEM)- The SEM facilities are housed in the department of Materials Science and Engineering at Lehigh University. The primary instrument used in this study is a JEOL 6300F. The JEOL 6300F is a state-of-the-art digital field emission gun SEM designed for high resolution $(1.5 \mathrm{~nm})$ imaging of coated samples at 30 $\mathrm{keV}$ and low voltage medium resolution $(6 \mathrm{~nm})$ imaging of beam-sensitive materials. Image storage is available on hard disc, as well as computerized image analysis and image processing. The $6300 \mathrm{~F}$ is interfaced with a windowless Link detector. The ability to detect low atomic number elements (such as oxygen) has proven to be invaluable for this study.

Electron Microprobe Analysis (EMP)- The EMP facility at John Hopkins University and its operation have been described in Iton and Veblen (in review), and Veblen and Ilton (DOE progress report for 1991).

$X$-ray Photoelectron Spectroscopy (XPS)- The XPS facility is housed in the Zettlemoyer Center for Surface Studies, Sinclair Laboratory, at Lehigh University. The facility is an ESCA-300, which is the most advanced ESCA instrument available. We will provide details of the facility on request (i.e., a pamphlet from the manufacturer). 
Fluid analysis- Fluid analysis facilities are housed in the Department of Earth and Environmental Sciences (formerly Geological Sciences) at Lehigh University. 'The laboratory's ion chromatograph consists of a Waters 510 HPLC pump, a Waters 712 automated sample processor (WISP), a Waters 430 conductivity detector, a Waters Reagent Delivery Module (for post-column derivatization), a Waters 490 spectrophotometer, a Kipp and Zonen BD40 strip chart recorder, and a Dynamic Solutions 810 PC AT-based chromatography workstation. An ARL 34000 inductively-coupled plasma atomic emission spectrophotometer with 40 pre-set channels and a SPEX scanning monochromator are available for a large number of cation and other analyses; the instrument includes an automated sample injector and HF-resistant nebulizers, and it is controlled by a DEC PDP-11 minicomputer. Laboratory analytical facilities in the hydrogeochemistry laboratory include Sequoia-Turner 340 and Leitz model M visible wavelength spectrophotometers (colorimeters) and a programmable Waters 4904 -channel flow-through uv-visible wavelength spectrophotometer with pulsed xenon light source.

TEM, SEM, EMP, and XPS sample preparation- Sample preparation for TEM, SEM and EMP have been described in detail in Ilton el al. (in press), Ilton and Veblen (in review), and Veblen and Ilton (DOE progress reports for 1990 and 1991). One difference is that we mounted samples from the silver, chromium, and selenium experiments on copper grids for TEM observation, whereas copper-rich samples were mounted on silver grids.

Sample preparation for XPS was simple. Rinsed flakes of reacted biotite were placed on a gold plated platform and secured in place by a dab of carbon paint. The mounted samples were held in a dessicator until the XPS session. Gold plating the platform facilitates locating the borders of the biotite specimen. 
Experimental Design - The design of these reconnaissance experiments is similar to that described in our research proposal. We have made a few modifications to the reaction chamber. The reaction chamber is a 1 liter, wide-mouth, polyethylene vessel; the platform holding the biotite flakes is a Playtex disposable baby bottle (polyethylene), cut to size and glued to the lid of the vessel. The baby bottles have screw-on nipple holders which, in our case, serve to secure two pieces of $150 \mu \mathrm{m}$ polypropylene mesh on either side of the biotite flakes. When the lid with the baby bottle is screwed onto the reaction vessel, the biotite flakes are immersed in solution and sit just above a stir bar. The sides of the baby bottles have been partially cut out, in order to facilitate fluid circulation. All the plastic-ware (reaction vessels, baby bottles, polypropylene mesh, and teflon stir bars) were boiled to extract organic plasticizers and then acid washed, prior to the experiments. The reaction vessels were placed in a water bath, which in turn sits on a six-position magnetic stirrer (i.e., we can run six experiments simultaneously). Continuously-stirred-flow-thru reactors were used in the copper experiments and batch reactors were used in the silver, selenium, and chromium experiments. Upon extraction, excess solution was wicked away with a Kim Wipe. The biotite flakes, along with the platform, were then copiously rinsed in a stream of millipore water. After being rinsed the biotite flakes were air dried and stored in closed polyethylene capsules.

Because the ICP is undergoing an upgrade, the solutions have been stored in a cold room. We will analyze them when the ICP comes back on line. Our priority has been to analyze the reacted biotites with TEM, SEM, and XPS. pH was meaured at the start and end of each experiment. The $\mathrm{pH}$ values remained essentially constant during the course of the experiment because of the high fluid/rock rations (see Table 1).

Experimental conditions- The experimental conditions are summarized in Table 1. The experiments were performed at $25^{\circ} \pm 3^{\circ} \mathrm{C}$ and $1 \mathrm{~atm}$., kept open to the atmosphere, and continually stirred. All the experiments used low-F biotites; the silver, selenium, and chromium experiments used biotite specimen HH7 (from Hoda and Hood, 1972) and the 
Table 1: Experimental set up

\begin{tabular}{|c|c|c|c|c|c|c|c|c|}
\hline Experiment & biotite & $\underset{(\mathrm{g})}{\operatorname{starting} \text { mass }}$ & sol. & $\begin{array}{l}\text { sol. conc } \\
(\mathrm{g} / \mathrm{l})\end{array}$ & $\mathrm{pH}$ & $\begin{array}{l}\text { flow rate } \\
\text { (ml/hr) }\end{array}$ & $\begin{array}{c}\text { sol. vol. } \\
(\mathrm{ml})\end{array}$ & $\begin{array}{l}\text { time } \\
\text { (hrs) }\end{array}$ \\
\hline CuBi7A & HH7 & 1.22 & $\mathrm{CuSO}_{4}$ & 25.6 & 4.12 & 0.103 & 120 & 170 \\
\hline CuBi7B & $\mathrm{HH} 7$ & 1.22 & $\mathrm{CuSO}_{4}$ & 25.6 & 4.12 & 0.103 & 120 & 515 \\
\hline CuBi8A & HH7 & 1.26 & $\mathrm{CuSO}_{4}$ & 25.6 & 3.00 & 0.102 & 120 & 169 \\
\hline CuBi8B & $\mathrm{HH} 7$ & 1.26 & $\mathrm{CuSO}_{4}$ & 25.6 & 3.00 & 0.102 & 120 & 514 \\
\hline Ag1 & $\mathrm{HH} 30$ & 0.0205 & $\mathrm{Ag}_{2} \mathrm{~S}$ & 0.722 & 3.10 & batc & 500 & 93 \\
\hline $\mathrm{Ag} 2$ & HH30 & 0.019 & $\mathrm{Ag}_{2} \mathrm{SO}_{4}$ & 0.722 & 2.8 & batch & 500 & 185 \\
\hline $\mathrm{Se} 1$ & $\mathrm{HH} 30$ & 0.014 & $\mathrm{H}_{2} \mathrm{SeO}_{4}$ & 0.291 & $2.8^{\prime}$ & batch & 750 & 429 \\
\hline $\mathrm{Se} 2-1$ & HH3O & 0.0047 & $\mathrm{H}_{2} \mathrm{SeO}_{4}$ & 0.1 & 3.0 & batch & 700 & 20 \\
\hline $\mathrm{Cr} 1-1$ & HH3O & 0.0064 & $\mathrm{CrO}_{3}$ & 0.071 & 3.20 & batch & 700 & 21 \\
\hline
\end{tabular}

HH7 and HH30 are low-F biotites of Hoda and Hood (1972) 
copper experiments used biotite specimen HH30 (from Hoda and Hood, 1972). In all the experiments large books of biotite were used ( $\geq 4$ mesh).

The selenium and chromium experiments were designed to maximize the likelihood of reduction at the biotite surface and not in solution (i.e., due to $\mathrm{Fe}^{2+}(\mathrm{aq})$ ). This was accomplished by using only $4-20 \mathrm{mg}$ of large biotite flakes per experiment, maintaining $\mathrm{pH}$ values at 2.8-3.2, and by introducing chromium and selenium into solution via puratronic grade $\mathrm{CrO}_{3}$ (Johnson and Matthey batch \#75072) and $\mathrm{H}_{2} \mathrm{SeO}_{3}$ (Johnson and Matthey batch \# S.89403D); these are the purest compounds available. Because $\mathrm{CrO}_{3}$ and $\mathrm{H}_{2} \mathrm{SeO}_{3}$ are acids, $\mathrm{pH}$ could be adjusted by measuring out appropriate amounts of these compounds (the compounds were weighed in a dry glove box because they are extremely toxic and deliquescent). Therefore, we minimized the chance of introducing anions that would either compete with the $\mathrm{Cr}$ - and Se-oxyanions for adsorption sites on the biotite surface or promote the dissolution of biotite (although bicarbonate was present because of we maintained open conditions). The very small biotite surface areas in the experiments and "moderate" $\mathrm{pH}$ values were employed to limit $\mathrm{Fe}^{2+}$ (aq) due to dissolution of biotite. The $\mathrm{pH}$ values were sufficiently low to promote adsorption (anion adsorption is enhanced at lower $\mathrm{pH}$ values).

$\mathrm{Ag}_{2} \mathrm{SO}_{4}$ (Johnson and Matthey batch \# S022132, puratronic grade) was used in the silver experiments in order to simulate the weathering of sulfide-ore deposits. $\mathrm{pH}$ was adjusted with sulfuric acid (ACS reagent.grade). The Cu experiments employed ACS reagent grade $\mathrm{CuSO}_{4}$.

\section{RESEARCH PROGRESS}

Our progress to date is divided into two major sections: (1) experimental results and (2) observations on natural copper-enriched minerals from the Cyprus Casa Grande porphyry copper deposit. Section (1) is subdivided into four parts: observations on biotites that have been reacted with (i) silver-bearing solutions, (ii) selenite-bearing solutions, (iii) chromate- 
bearing solutions, and (iv) copper-bearing solutions. Section (2) is subdivided into two parts: copper-enriched (i) feldspars and (ii) biotites.

\section{EXPERIMENTAL RESULTS}

We present initial results from experiments that were designed to elucidate the interaction of solutions bearing multivalent elements such as copper, silver, chromium (hexavalent $\mathrm{Cr}$ ), and selenium (selenite) with biotite. The specific goal of these initial experiments was to discover whether or not sorption of these elements involves oxidationreduction reactions at the surface and/or interior of biotite. Reduction of $\mathrm{Cu}^{2+}, \mathrm{Ag}^{+}, \mathrm{Cr}^{6+}$, and $\mathrm{Se}^{4+}$ to $\mathrm{Cu}$ metal, $\mathrm{Ag}$ metal, $\mathrm{Cr}^{3+}$, and native $\mathrm{Se}$, respectively, would pose severe constraints on the mobility, toxicity, and supergene enrichment of these elements. In order to assess the influence of fluorine on copper sorption by biotite, the copper experiments presented here utilized low-F biotite in contrast to the high-F biotite used by Ilton et al. (in press). All of the experiments were kept open to the atmosphere and as such represent the most robust test of biotite's ability to reduce these elements. The priority of these initial experiments was to characterize the surfaces and interiors of the reacted biotites with SEM, TEM, and XPS. The experimental conditions are summarized in Table 1.

\section{Silver}

We present results from TEM, SEM, and optical observations; we did not use XPS because the binding energies for the photoelectrons of $\mathrm{Ag}+$ and $\mathrm{Ag}^{\circ}$ cannot be resolved reliably. Experiments $\mathrm{Ag} 1$ and $\mathrm{Ag} 2$ were similar in all respects but one: prior to introducing the $\mathrm{Ag}$ into solution, the reaction vessel for $\mathrm{Ag} 1$ was acid washed with $\mathrm{HCl}$, whereas the reaction vessel for $\mathrm{Ag} 2$ was acid washed with $\mathrm{H}_{2} \mathrm{SO}_{4}$. The consequence of using these different procedures turned out to be very interesting and is described below. 
Visual inspection - Visual inspection of biotites from both $\mathrm{Ag} 1$ and $\mathrm{Ag} 2$ showed a silvery fringe that encircles the biotites. The silvery fringe tends to follow cracks into the interior portions of the biotite flakes.

SEM observations - EDS analyses of biotites from both $\mathrm{Ag} 1$ and $\mathrm{Ag} 2$ showed that the edges of the flakes were highly silver enriched; however, analyses of Ag1 also revealed high $\mathrm{Cl}$ concentrations at the edges, whereas analyses of $\mathrm{Ag} 2$ did not. SEM images of $\mathrm{Ag} 1$ show cubic precipitates on the surface of biotite that range up to $0.5 \mu \mathrm{m}$ in width (Figs 1a, 1b, and 1c). These precipitates are concentrated on the edge of the biotite flake (Fig. 1a) and along "micro-edges" (henceforth called ledges) on the basal plane of the biotite grain (Figs. $1 \mathrm{~b}$ and 1c). High $\mathrm{Ag}$ and $\mathrm{Cl}$ concentrations correlate with high densities of these cubic precipitates. Although we have not yet positively identified the $\mathrm{AgCl}$-rich particles, we note that $\mathrm{AgCl}(\mathrm{s})$ is sparingly soluble and cubic. Therefore we are reasonably certain that these precipitates are $\mathrm{AgCl}(\mathrm{s})$. We suspect that the reaction vessels were contaminated by $\mathrm{Cl}^{-}$despite repeated rinsing with millipore water after acid-washing with $\mathrm{HCl}$. Figure 1d shows a rare Ag-rich precipitate that is not associated with $\mathrm{Cl}$ and that displays a habit that we might expect for metallic silver. Note that this precipitate is linear and is following a crack in the surface of biotite.

SEM images of $\mathrm{Ag} 2$ are given in Figure 2. Note the numerous hexagonal platelets of $\mathrm{Ag}$-rich precipitates that cling to ledges on the biotite surface. Figure $2 \mathrm{bis}$ an ultrahigh resolution SEM image of a biotite ledge; the bright colliform features are Ag-rich. Figure 2d shows columnar Ag-rich precipitates that are clinging to and overgrowing a biotite ledge. In Figures $2 \mathrm{a}, 2 \mathrm{c}$ and $2 \mathrm{~d}$ there are "bright precipitates" and "fuzzy precipitates." The "fuzzy precipitates" are just below the surface of biotite and constitute evidence that the Ag-particles are located in the interlayer region as well as on the surface of biotite. EDS analyses of these general areas are represented by Fig. 3a. Note both the strong $\mathrm{Ag}$ and biotite components. Figure $3 \mathrm{~b}$ is an EDS analysis of a large Ag-rich precipitate ( $\geq 1 \mu \mathrm{m}$ dia.). Note that the $\mathrm{Ag}$ 
peak dwarfs all the other peaks and that the $\mathrm{Si} / \mathrm{O}$ ratio is the same as in Figure 3a. We consider this definitive proof that the $\mathrm{Ag}$-rich precipitates in $\mathrm{Ag} 2$ are, in fact. metallic silver. This is a beautiful demonstration of the usefulness of being able to detect light elements such as oxygen and the great resolution of the 6300F SEM.

TEM observations - TEM images of biotite from $\mathrm{Ag} 2$ were obtained perpendicular to the basal plane of biotite by pealing the biotite layers apart with sticky tape until the remaining layers were electron transparent. Note that we imaged areas that were interior portions of biotite during the experiments. Figure 4 reveals numerous metallic silver inclusions that show polygonal morphologies that are reminiscent of the native copper inclusions discussed in Ilton et al. (in press) and Ilton and Veblen (DOE 1991 progress report). Figure 5 is a TEM image of a $\mathrm{Ag}$ precipitate that is sandwiched between two or more biotite layers. Electron diffraction patterns obtained from this particle are consistent with metallic silver.

Discussion - Although more work is required (see section on Future Work) to define all the reactions involved, it is clear that $\mathrm{K}$-rich biotite is capable of sorbing silver from solution and subsequently reducing $\mathrm{Ag}+$ to metallic $\mathrm{Ag}$ under conditions $\left(\mathrm{T}, \mathrm{pH}\right.$, and $\mathrm{SO}_{4}$ concentrations) that are similar to those associated with the weathering of sulfide-ore deposits. As with the copper experiments, $\mathrm{Fe}^{2+}$ in the octahedral sites of biotite is the only likely reducing agent. We suspect that other noble metals and the platinum group elements might behave in a similar fashion.

The presence of $\mathrm{AgCl}$ on the surface of biotite indicates that $\mathrm{Fe}^{2+}$ in biotite is not capable of reducing $\mathrm{AgCl}$. The explanation for this is readily apparent; the standard potential for the half reaction $\mathrm{AgCl}+\mathrm{e}^{-}=\mathrm{Ag}+\mathrm{Cl}^{-}$is 0.2223 , which is appreciably lower than the half cell potential for $\mathrm{Fe}^{3+}$ (hydroxide) $+\mathrm{e}^{-}=\mathrm{Fe}^{2+(\text { biotite) }}$ estimated by White and Yee (1985). 

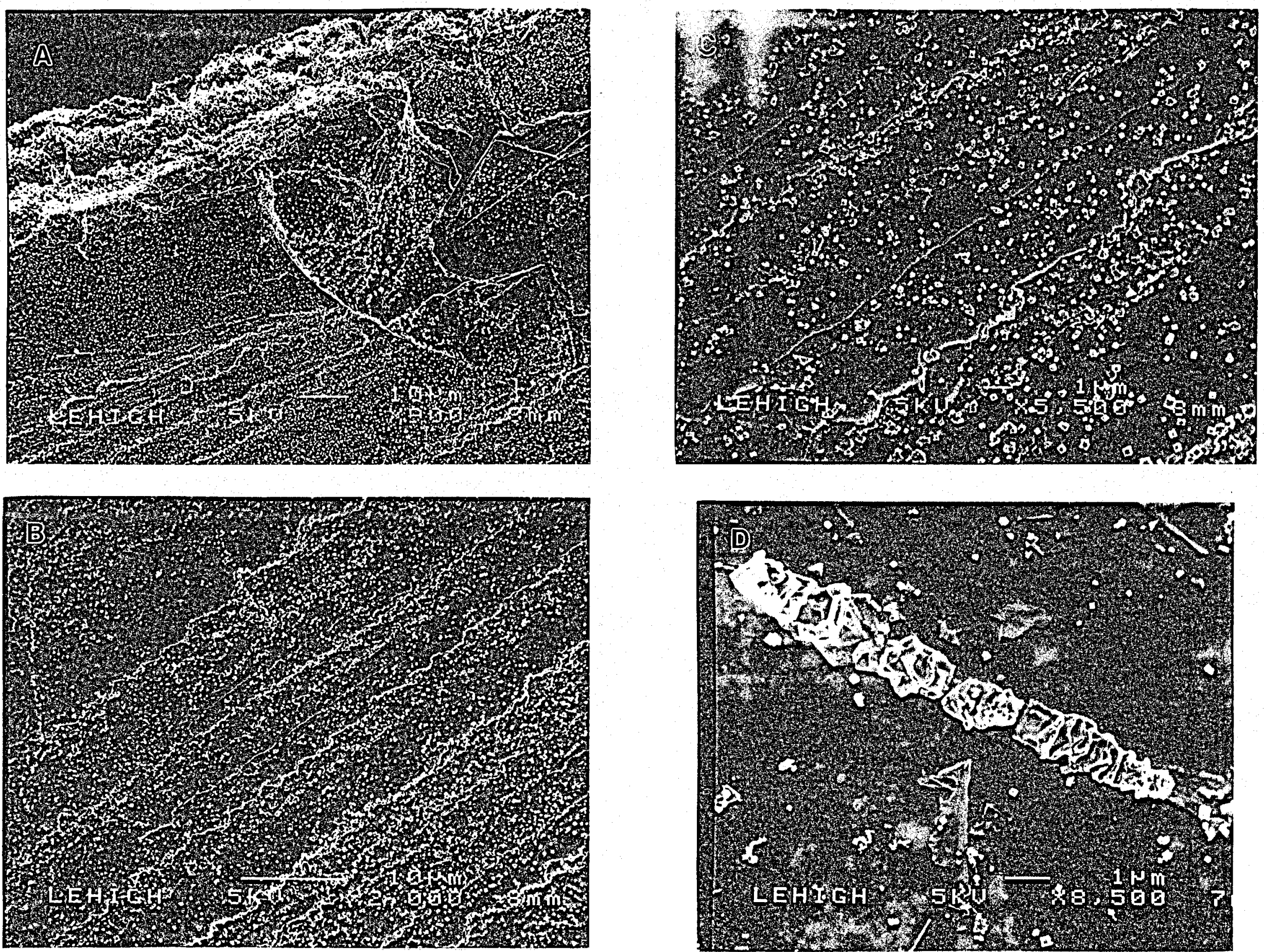

Fig. 1: SEM images of biotite (Ag1): images (A) - (C) show cubic AgCl-rich precipitates on biotite surface. Image (D) shows Ag-rich (probably metallic silver) precipitate following crack on biotite surface. 

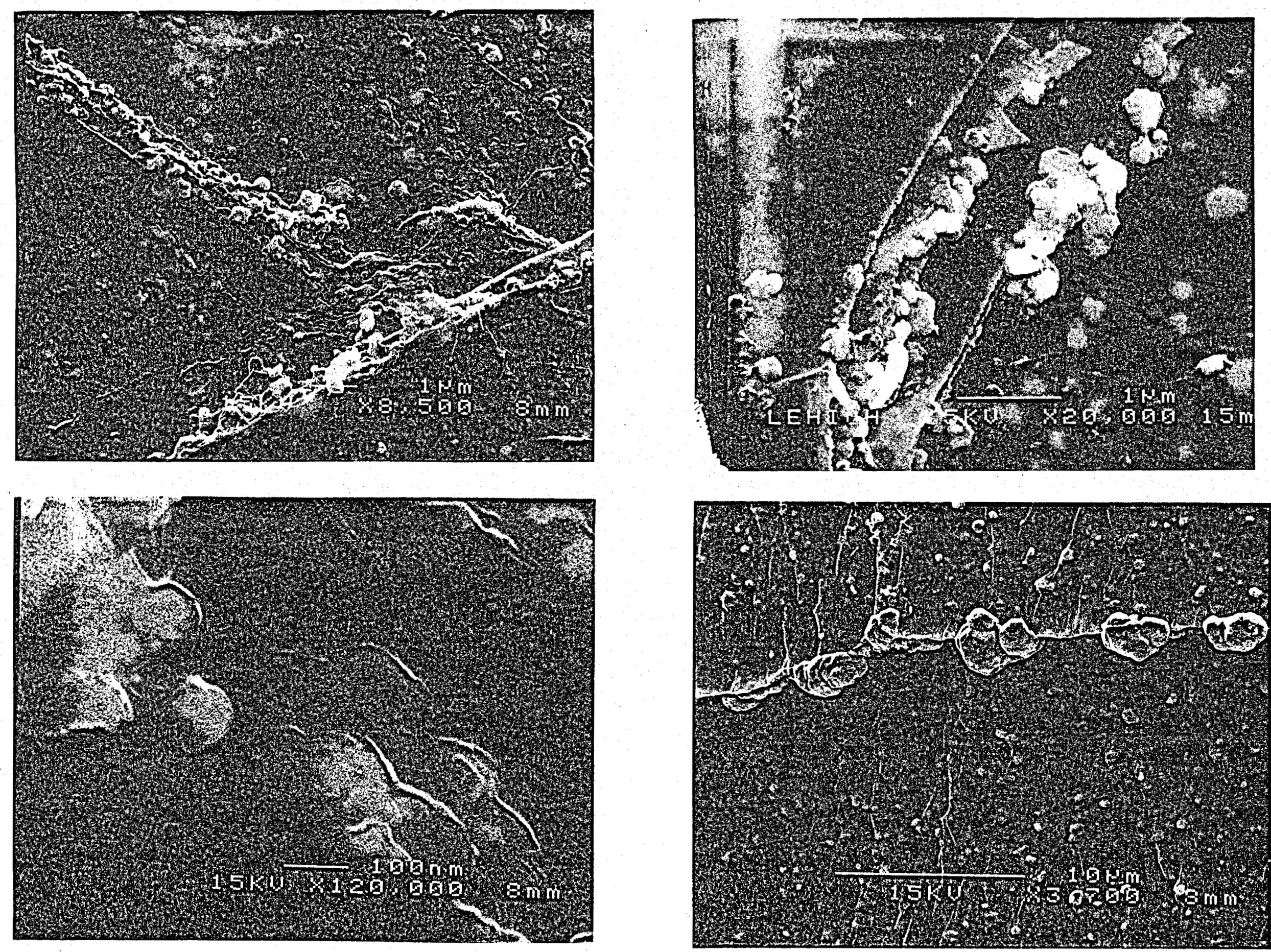

Fig. 2: SEM images of metallic-silver precipitates on and under the surface of biotite (Ag2). 

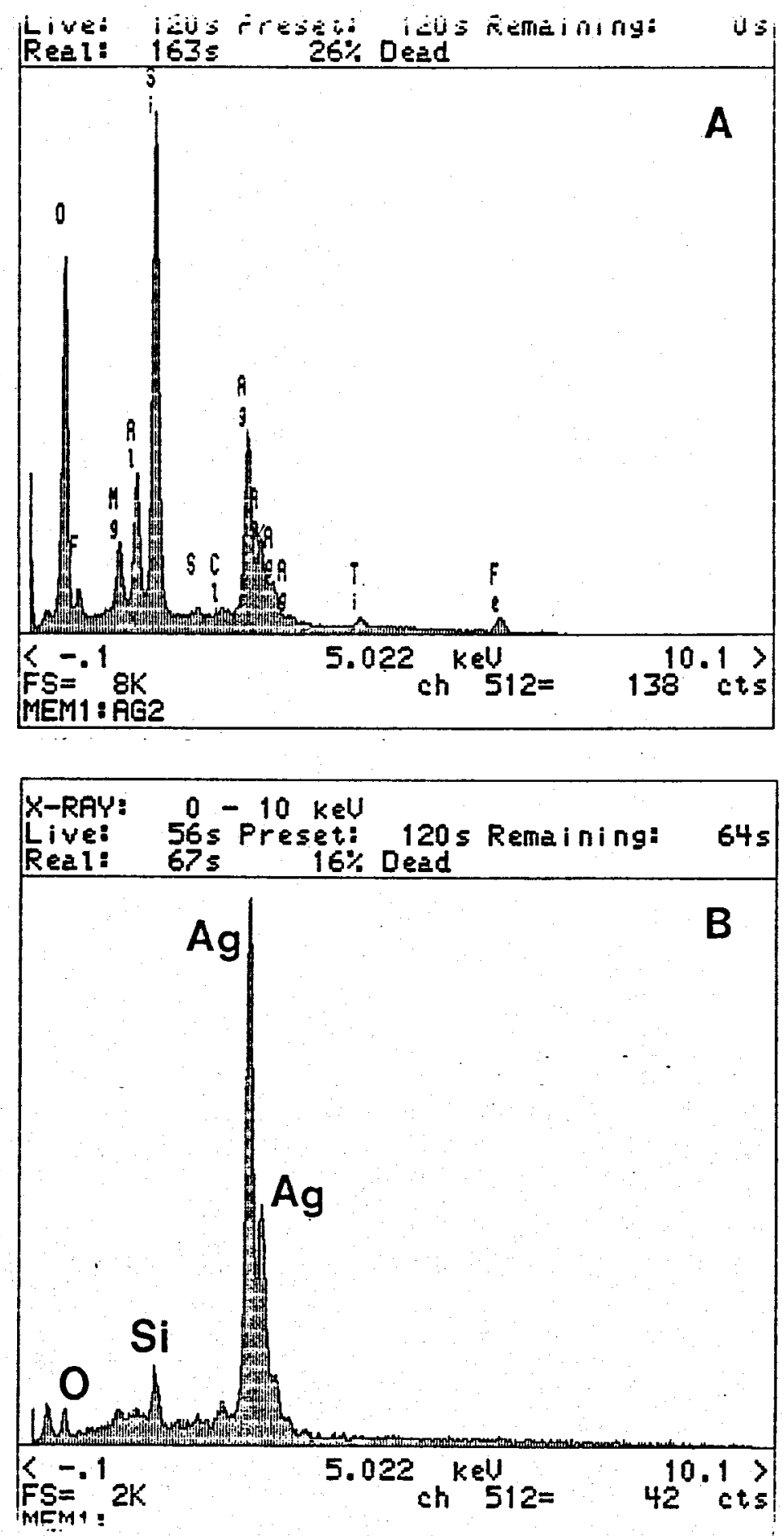

Fig. 3: EDS analysib of biotite (Ag2) surface: (A) general area; (B) close up analysis of "large" silver-precipitate. 




\section{Selenium}

Visual inspection - Visual observations of biotite flakes from the selenium experiments do not reveal any dramatic changes. The longer term Se experiments (Se1) indicate that some exfoliation has occurred. Se1 also shows a thin lighter fringe at the edge which makes an abrupt transition to a thin-dark-green fringe toward the interior of the flake. This is classic , evidence for a coupled leached outer zone and oxidation-reduction front in weathered biotite.

SEM observations - An SEM/EDS survey of Se1 indicates that selenium is associated with edges and ledges, and with an alumino-silicate phase (precipitate?) that dots the surface of biotite.

TEM observations - TEM observations of selenium-enriched edges of biotites from Se1 do not reveal any inclusions or precipitates. This indicates that the selenium is either adsorbed by or incorporated into the biotite flake.

XPS observations - The photoelectron binding energies for $\mathrm{Se}^{4+}$ species and native $\mathrm{Se}$ can be readily resolved by XPS analysis. Figure 6 is a general XPS spectrum of a biotite surface from experiment Se1; the boxed area contains the Se photoelectron peaks of interest. Figure 7, which corresponds to the boxed area in Figure 6, shows a background spectrum representative of unreacted biotite (marked by crosses) and three distinct photoelectron peaks that correspond to the Se auger, Se 3p1, and Se 3p3 binding energies for Se4+.

XPS analysis of a biotite surface from a short-term experiment (Se2-1) is shown in Figure 8. Comparison of unreacted and briefly reacted biotite spectra do not reveal detectable levels of selenium on the surface of Se2-1.

Discussion - Because the solutions contained $\mathrm{Se}^{4+}$ and XPS analysis of the biotite surface yielded $\mathrm{Se}^{4+}$, the XPS results do not provide evidence for the reduction of selenium on 


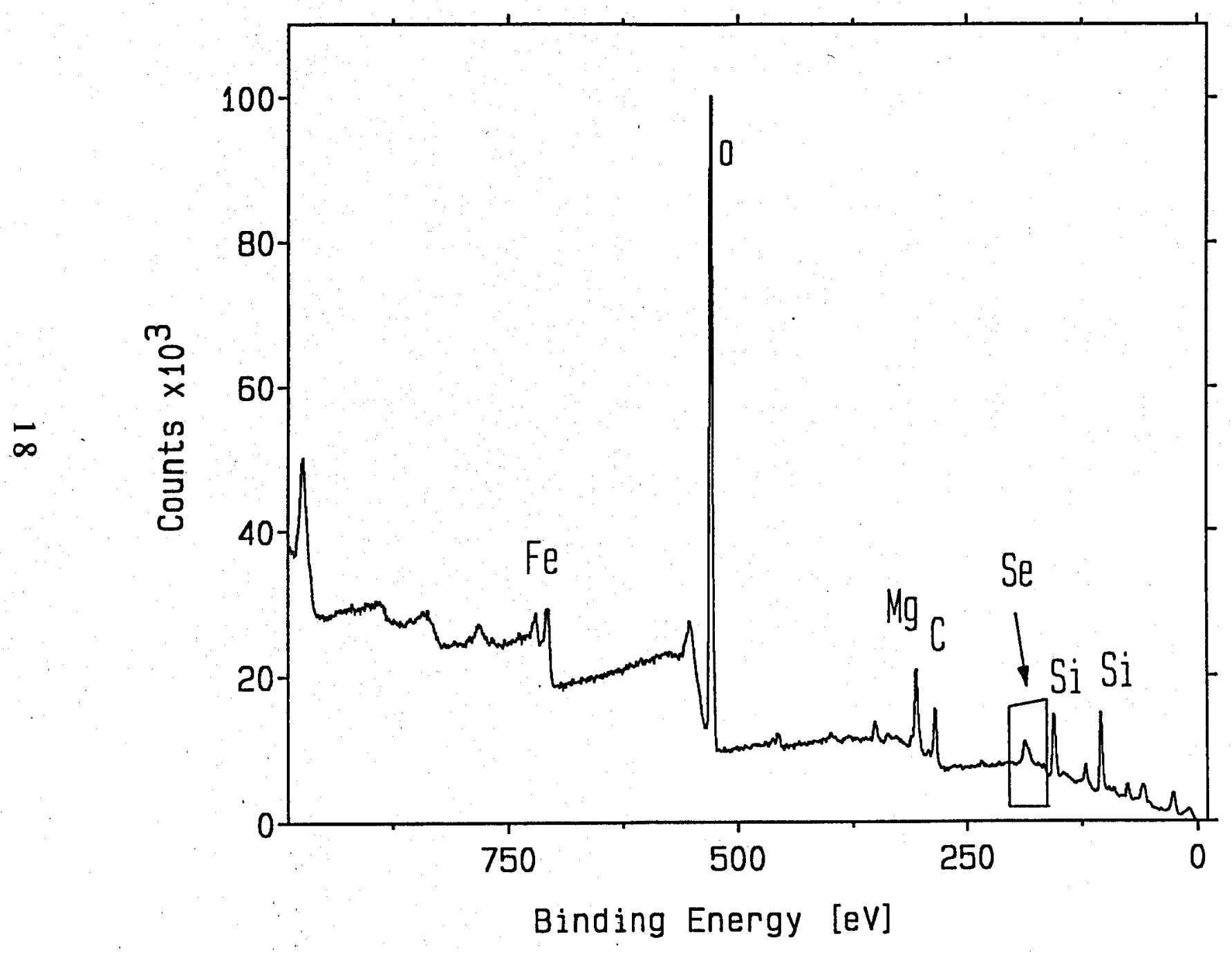

\begin{tabular}{|c|}
\hline Pass energy \\
$500 \mathrm{eV}$ \\
Slit width \\
$1.1 \mathrm{~mm}$ \\
Energy step \\
$1.00 \mathrm{eV}$ \\
Det. height \\
$70 \%$ \\
Lens mode \\
SPATIAL \\
x-ray power \\
$7.9 \mathrm{~kW}$ \\
Rec. time \\
o0: $10: 18$ \\
\hline
\end{tabular}

Fig. 6: A general XPS spectrum of a biotite (Se1) surface that has been reacted with a selenite-bearing solution. 


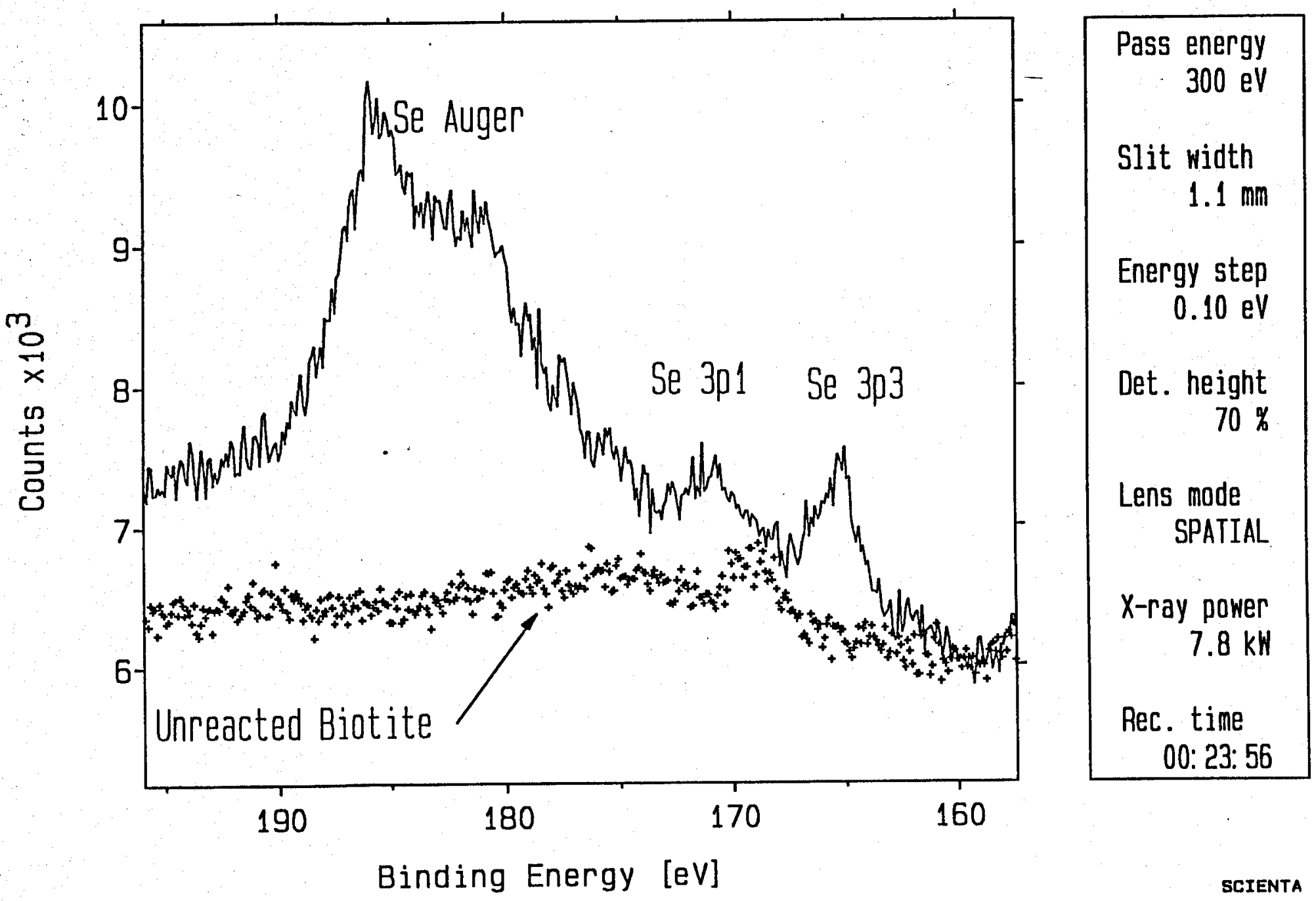

Fig. 7: A XPS spectrum of a biotite (Se1) surface that has been reacted with a selenite-bearing solution is given by the solid line. The spectra corresponds to the boxed-in area from Fig. 6 . The binding energies of the auger, $3 \mathrm{p} 1$, and $3 \mathrm{p} 3$ photoelectron peaks for selenium indicate that the oxidation state of sorbed selenium is +4 . A background spectrum from an unreacted biotite surface is given by the crosses. 
N

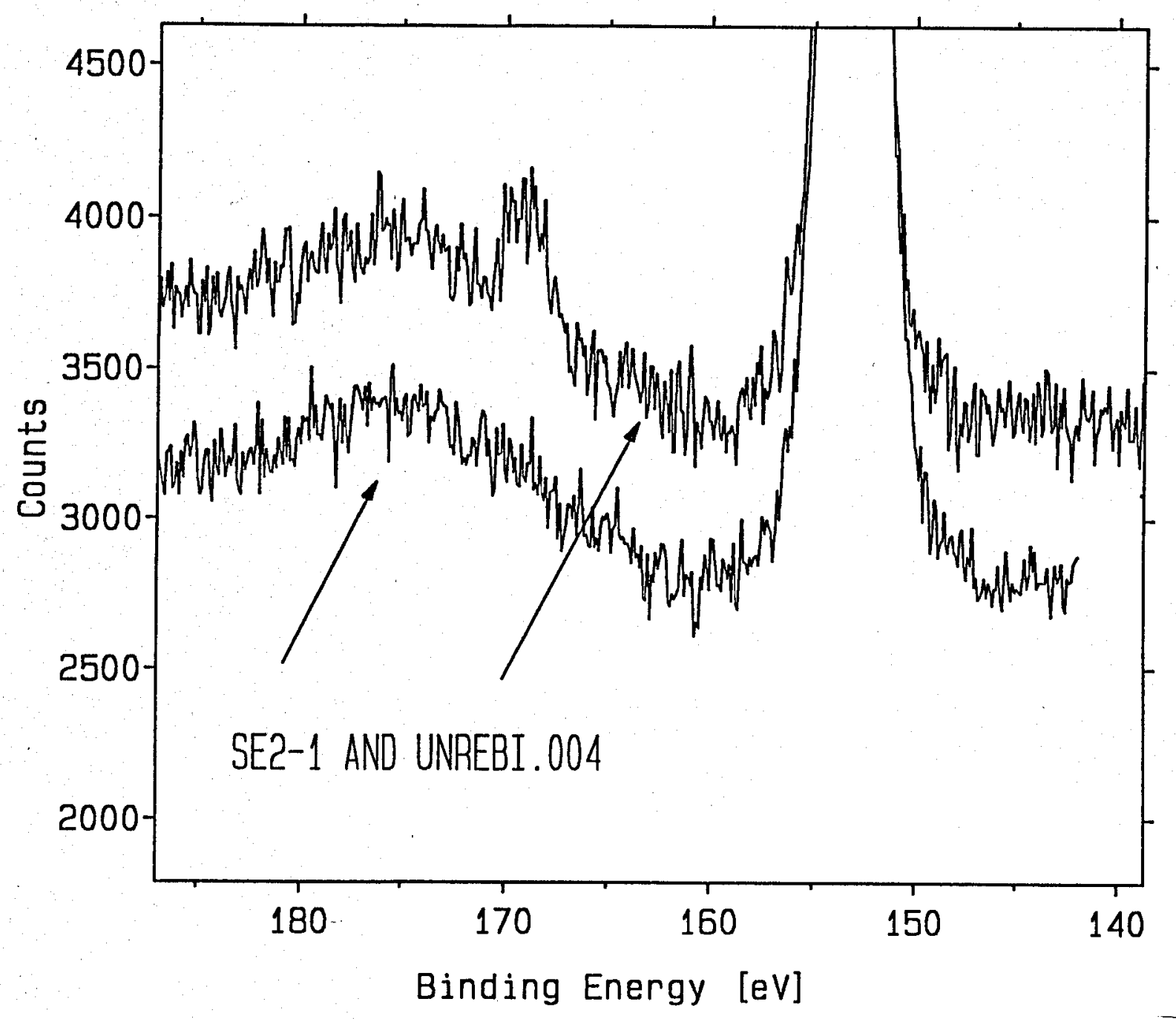

\begin{tabular}{c} 
Pass energy \\
$300 \mathrm{eV}$ \\
Slit width \\
$1.1 \mathrm{~mm}$ \\
Energy step \\
$0.10 \mathrm{eV}$ \\
Det. height \\
$100 \%$ \\
Lens mode \\
SPATIAL \\
x-ray power \\
$6.4 \mathrm{~kW}$ \\
Aec. time \\
o0: $11: 46$ \\
\hline
\end{tabular}

Fig. 8: XPS spectra of an unreacted biotite surface and a biotite (Se2-1) surface that has been reacted briefly with a selenite-bearing solution. There is no evidence for Se sorption. 
the surface of biotite. The results from this experiment, however, do not necessarily mean that reduction has not occurred; it is possible that reduction of $\mathrm{Se}^{4+}$ to $\mathrm{Se}^{\circ}$ occurred at some stage of the experiment, but that $\mathrm{Se}^{\circ}$ was reoxidized either during a later stage of the experiment or during the extraction procedure. The reader is reminded that both the experimental conditions and the extraction process were robustly oxidizing and that $\mathrm{Se}^{\circ}$ is unstable under these conditions. In the section Future Work we discuss ways in which we can fine tune the experiments in order to answer some of these questions.

\section{Chromium}

We present results from SEM, XPS and optical observations. We intend to study biotite from the chromium experiments with TEM in the near future.

Visual inspection - Cr1-1 was a short-term experiment. The biotite flakes appeared unaltered to the eye. We have not yet studied the longer term experiments (Cr1-2).

SEM observations - Qualitative EDS analyses (see Figure 9) and SEM observations indicate that chromium is associated with the edges of the biotite flake and ledges on the surface of biotite. Chromium is also associated with smaller biotite grains that have stuck to the surface of the larger biotite flake (Figure 10). We suspect that chromium is associated with these small grains because they contain a high concentration of edge sites. Thusfar, we have not observed any discrete chromium-rich precipitates.

XPS observations- XPS analyses of the surface of biotite from Cr1-1 detected measurable chromium, whereas XPS analysis of the surface of an unreacted biotite did not detect $\mathrm{Cr}$. Figure 11 is an XPS spectrum of Cr1-1 (solid line) and an unreacted biotite surface (crosses); the two peaks are associated with the reacted biotite surface and correspond to binding energies for photoelectrons $\mathrm{Cr} 2 \mathrm{pl}$ and $\mathrm{Cr} 2 \mathrm{p} 3$. The binding energies for $\mathrm{Cr} 2 \mathrm{p} 1$ and 
$\operatorname{Cr} 2 \mathrm{p} 3$ unequivocally demonstrate that a $\mathrm{Cr}^{3}+$ species is sorbed on the surface of the biotite flake from experiment $\mathrm{Cr} 1-1$. Moreover, the binding energies most closely match those for a Cr-hydroxide species; however, to distinguish among the possible trivalent chromium species with any certainty will require much more work.

Table 2 lists results from angle-resolved XPS analyses from the surface of a biotite grain from Cr1-1. We analyzed the biotite surface as a function of the angle-of-incidence of the $\mathrm{X}$-rays relative to the basal plane of biotite. $66 \%$ of the compositional information originates over $\sim 30,15$, and $5 \AA$ depth from the surface of "biotite" for X-ray angle-of-incidences of $90^{\circ}$, $30^{\circ}$, and $10^{\circ}$, respectively; not enough signal to analyze is generated at angles less than $10^{\circ}$. All material surfaces, except in the highest of vacuums, are coated with a monolayer of adventitious carbon (considered to be inert forms of carbon). Therefore, it is not surprising that carbon concentrations increase with decreasing angles-of-incidence. The fact that $\mathrm{Cr} /(\mathrm{Si}+$ $\mathrm{Fe}$ ) ratios increase as we sample more of the top surface and less of the bulk (i.e., $90^{\circ}-->10^{\circ}$ ) is strong evidence that chromium is sorbed at the surface of biotite and is not incorporated deeply into the bulk structure of biotite. Figure 12 illustrates the compositional change in the system Si-Fe-Cr as a function of the depth of the analyses (or angle-of-incidence).

The results from angle-resolved XPS also yield important information on the composition of the sorbed chromium species. It is particularly important to determine if the sorbed chromium phase is a solid solution of $\mathrm{Fe}$ and $\mathrm{Cr}$, because the solubility of $\mathrm{Cr}$ oxyhydroxides are strongly limited by Fe in solid solution (Sass and Rai, 1987). Table 2 and Figure 12 show that $\mathrm{Cr} / \mathrm{Fe}$ ratios increase with decreasing depth of analysis. At $10^{\circ}, \mathrm{Cr}$ and Fe concentrations are 38.1 and 61.9 atomic $\%$, respectively, for $\mathrm{Cr}+\mathrm{Fe}=100 \%$. Therefore, if a $\mathrm{Cr}$-Fe solid solution is present, then the most $\mathrm{Fe}$ and the least $\mathrm{Cr}$ in solid solution are $61.9 \%$ and $38.1 \%$, respectively (accuracy $\approx \pm 20 \%$ ). In fact, we suspect that very little, if any, $\mathrm{Fe}$ is associated with $\mathrm{Cr}$, because the SEM/EDS study indicates that $\mathrm{Cr}$ is unevenly distributed on the biotite surface. The $\mathrm{Cr} / \mathrm{Fe}$ compositional information gathered by XPS (and 

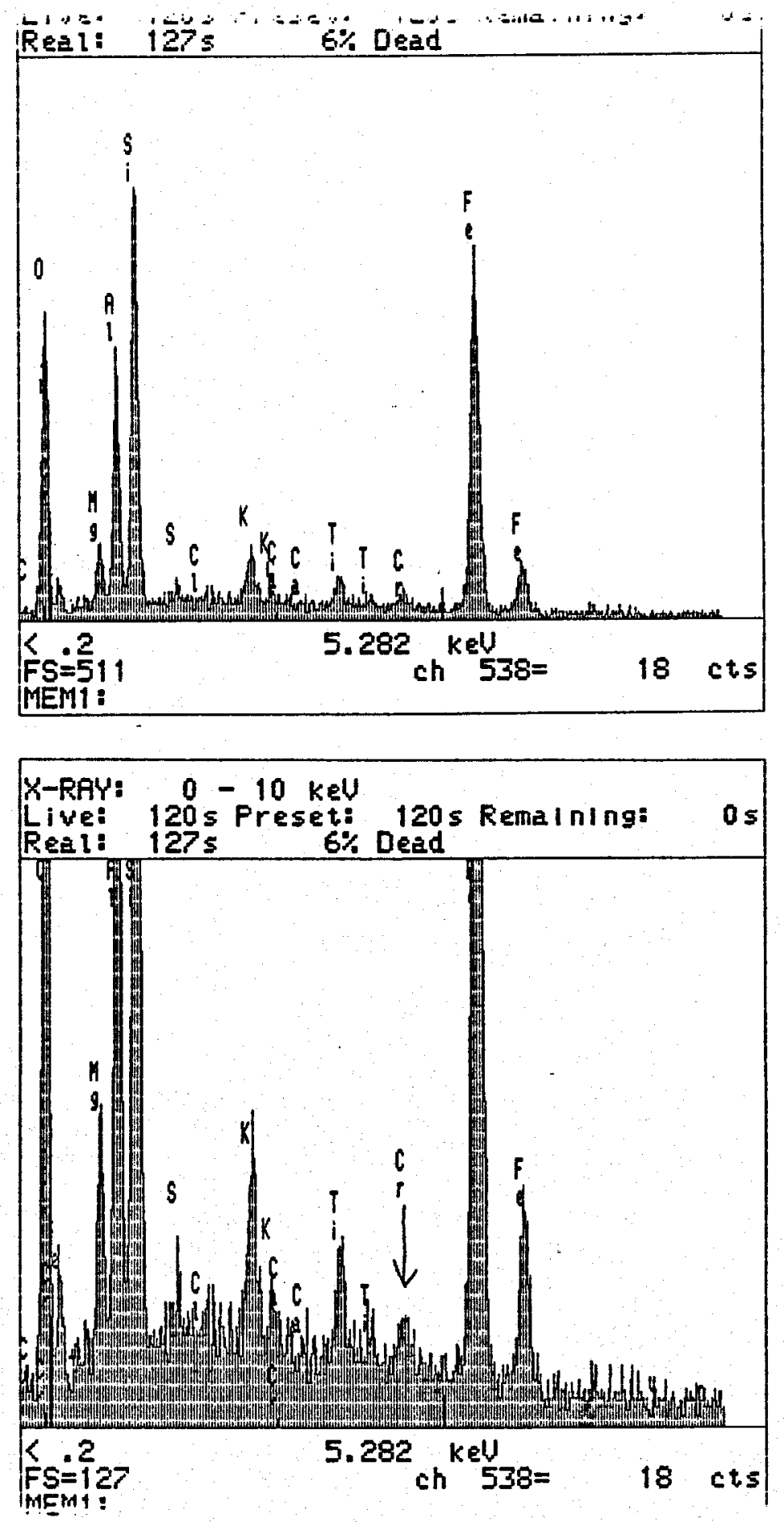

Fig. 9: EDS analysis of the edge of a biotite flake (Cr1-1) that has been reacted with a hexavalent chromiumbearing solution. Note the discernable chromium peak 

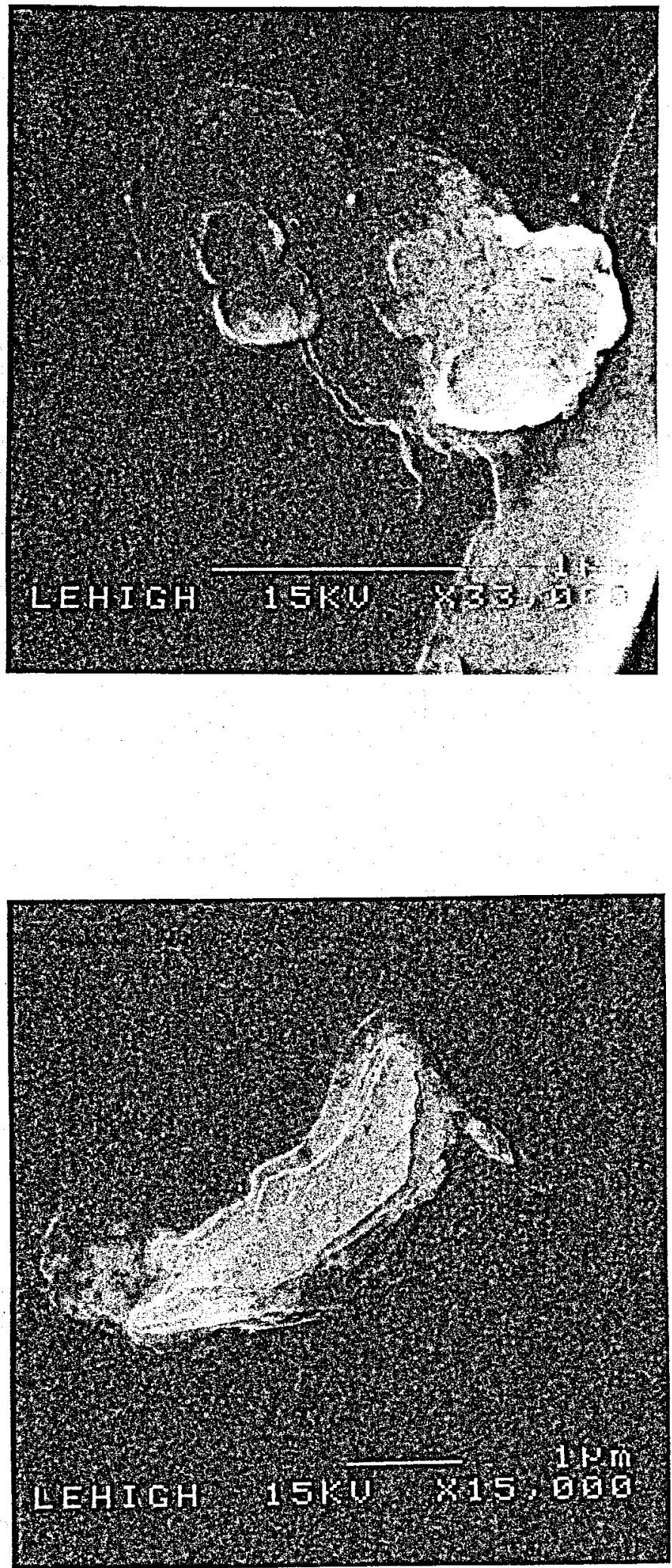

Fig. 10: SEM images of the surface of a biotite flake (Cr1-1) that has been reacted with a hexavalent chromium-bearing solution. Both images show a small biotite grain sitting on the surface of a larger biotite flake. Measurable chromium is associated with the smaller biotite grains. 


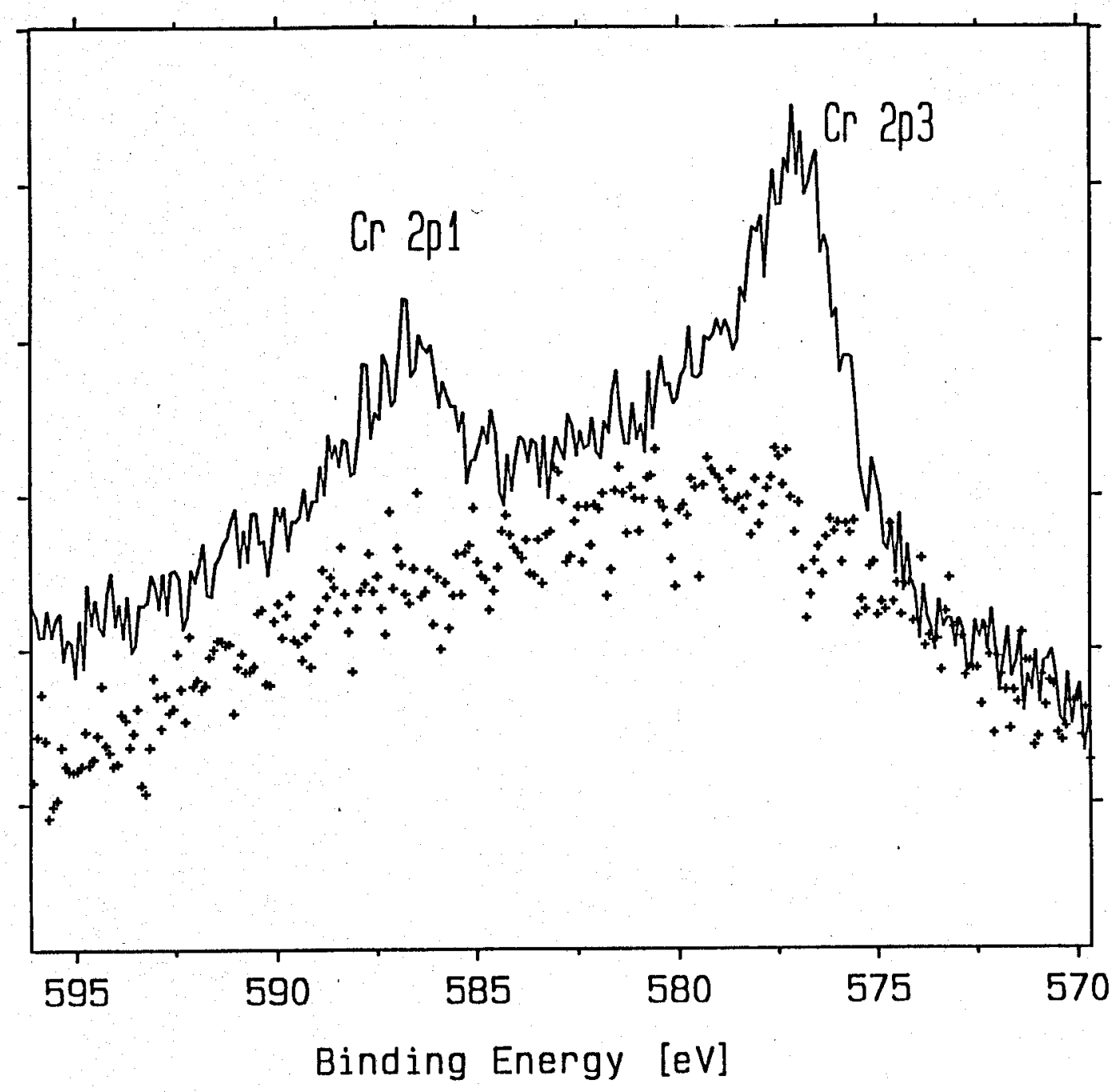

Pass energy $300 \mathrm{eV}$

Slit width $1.1 \mathrm{~mm}$

Energy step $0.10 \mathrm{eV}$

Det. height $90 \%$

Lens mode SPATIAL

$X$-ray power $7.2 \mathrm{~kW}$

Rec. time

01: 11: 49

Fig. 11: XPS spectrum of a biotite (Cr1-1) surface that has been reacted with a hexavalent chromium-bearing solution is given by the solid line. The binding energies for the $\mathrm{Cr} 2 \mathrm{p} 1$ and $\mathrm{Cr} 2 \mathrm{p} 3$ photoelectrons indicate that the sorbed chromium species has $a+3$ oxidation state. A spectrum for an unreacted biotite surface is given by the crosses. 
Table 2. Results from XPS analysis of biotite surface that has been reacted with a solution bearing hexavalent chromium. The relative concentrations of $\mathrm{Cr}, \mathrm{Fe}, \mathrm{Si}$, and $\mathrm{C}$ on the surface of biotite are given as a function of the angle of incidence of the X-rays relative to the basal plane of biotite.

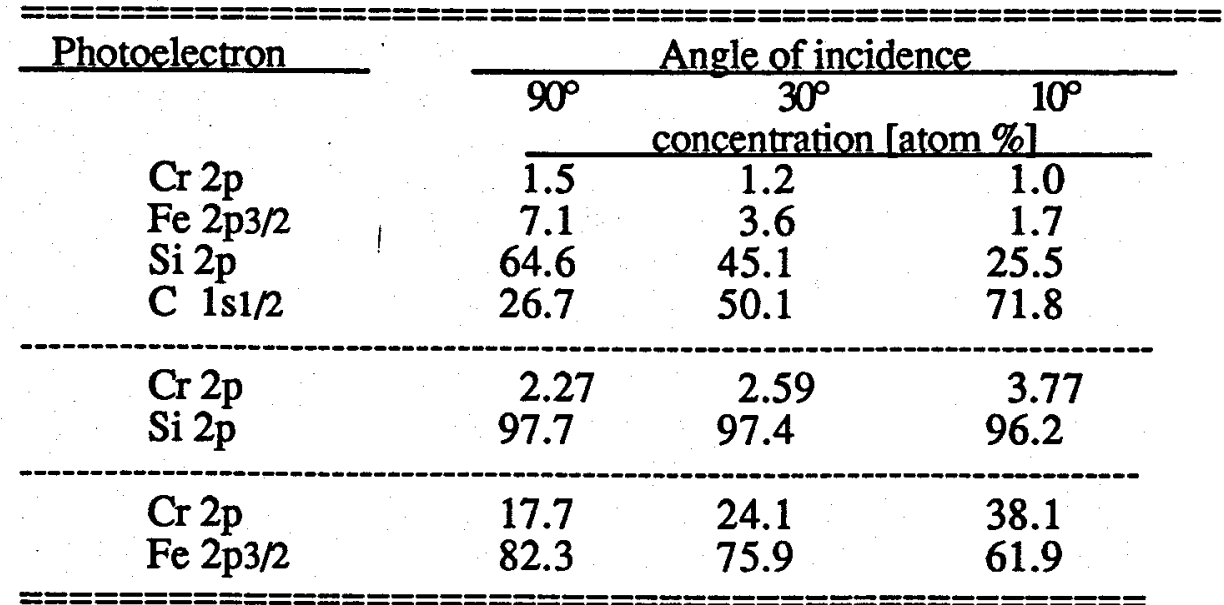

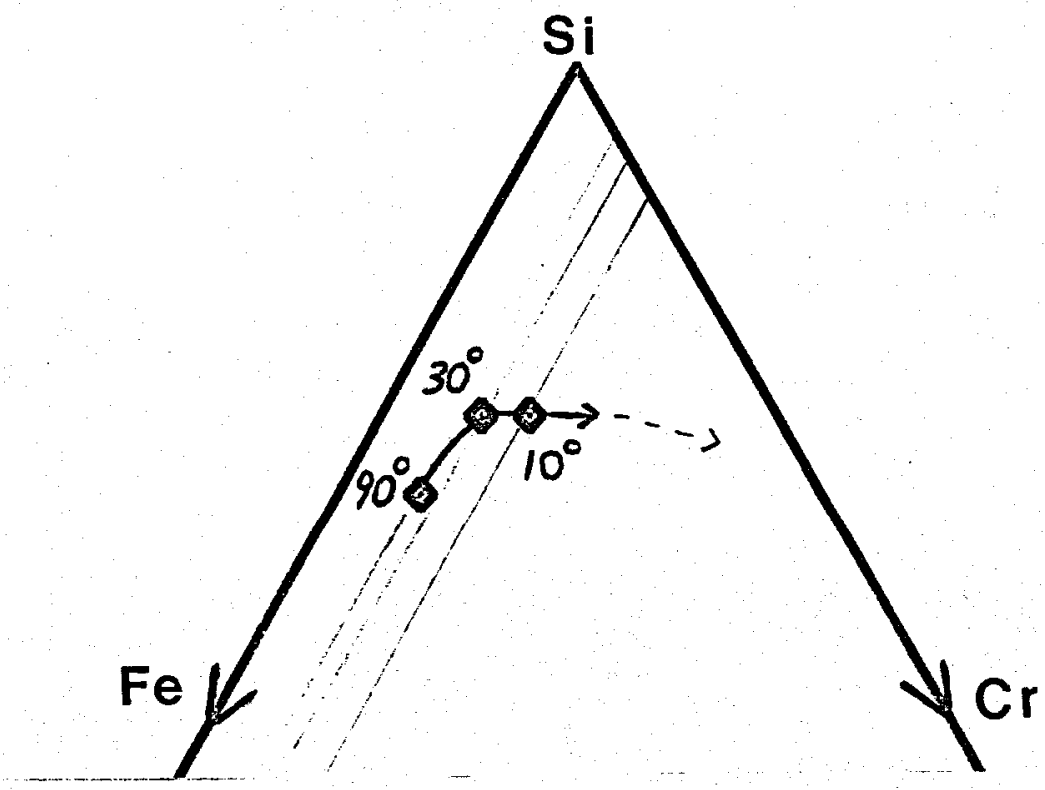

Fig. 12: A triangular diagram in the system $\mathrm{Si}-\mathrm{Fe}-\mathrm{Cr}$ which gives the surface composition of biotite (Cr1-1) as a function of the angle-of-incidence of X-rays for XPS analyses. Note that the analyses become enriched in chromium relative to silica and iron with decreasing angles (i.e., decreasing signal depth below surface of biotite). This indicates that chromium is at the surface of biotite and not incorporated deeply in the structure of the mineral. 
EDS/SEM) along with solubility data on $\mathrm{Cr} / \mathrm{Fe}$ - hydroxides (Sass and Rai, 1987) indicates that our experimetnal solutions must have been undersaturated with respect $\mathrm{Cr} / \mathrm{Fe}$-hydroxide.

Discussion - Because the dominant cation in solution was $\mathrm{Cr}^{6+}$, the XPS results are consistent with, but not yet definitive proof for, the sorption of and subsequent reduction of $\mathrm{Cr}^{6+}$ (aq) to $\mathrm{Cr}^{3+}$ at the surface of biotite. In the section Future Work, we discuss a number of experiments that are required to fully understand the processes occurring in the experiments.

\section{Copper}

Low -F biotite experiments (published, in part, in abstract form by Earley, Ilton, Marozas, and Veblen, 1991)- In this study, low-F (0.4 wt.\% F) biotites were reacted with acidic $\mathrm{CuSO}_{4}$ solutions (see Table 1 for experimental conditions) at $25^{\circ} \pm 3^{\circ} \mathrm{C}$ and $1 \mathrm{~atm}$., in mixed flow reactors open to the atmosphere, in order to compare $\mathrm{Cu}$ absorption rates and reaction mechanisms with similar experiments performed on high-F ( $2.5 \mathrm{wt}$ \% F, BANBI) biotites (Ilton et al, in press). Moreover, biotites in porphyry copper systems commonly have F-poor compositions. It is well established that $\mathrm{F}$ stabilizes biotite in weathering environments; however, the effect of $F$ on transition-metal uptake by sheet silicates is unknown.

After one week of reaction, SEM and electron microprobe analyses of run products from the $\mathrm{pH}=3(\mathrm{CuBi} 8 \mathrm{~A})$ and $4.12(\mathrm{CuBi7A})$ experiments, show that up to 5 wt. \% Cu occurs within $250 \mu \mathrm{m}$ of the edge of low-F biotites (Figures 13a and 14a). Cu is distributed heterogeneously along preferred lenticular zones as in the high-F biotite experiments. Electron microprobe analyses indicate that $\mathrm{Cu}$ uptake is strongly correlated with $\mathrm{K}$ loss but is independent of all other cations (Figures. 15a and 16a?).

TEM observations (Figure 17) indicate that low-F biotites contain bigger and denser arrays of native copper inclusions than high-F biotites (compare to Figure.10 in DOE progress report 1991). Whereas copper-enriched domains in high-F biotite are strictly correlated with native copper inclusions, low-F biotites have copper enriched domains (up to $3.6 \mathrm{wt} \% \mathrm{CuO}$, 
by AEM) that are free of native copper inclusions, but that contain numerous expanded interlayers. AEM analyses of these areas in low-F biotites show that $\mathrm{Cu}$ and $\mathrm{K}$ are inversely correlated (Figure 18). Moreover, TEM observations indicate that copper concentrations are positively correlated with an increasing density of expanded interlayers.

After 3 weeks of reaction the biotites in the $\mathrm{pH}=3$ and 4.12 experiments display radically different behaviors. At both $\mathrm{pH}$ values, biotite appears to lose $\mathrm{Cu}$ relative to biotite in the 1 week experiments (Figures. 13 and 14). However, biotite at $\mathrm{pH}=4.12$ loses nearly all of its copper (Figure 14b), whereas biotite at $\mathrm{pH}=3$ (Figure 13b) still retains, on average, an order-of-magnitude higher copper concentrations than high-F biotites under similar conditions (see $1991 \mathrm{DOE}$ progress report ; Ilton et al., in press). In fact, at $\mathrm{pH}=4.12$, the $\mathrm{Cu}-\mathrm{K}$ exchange reverses in biotite and the $\mathrm{Cu}$-enriched fringe is replaced by a $\mathrm{Cu}$-poor illitic fringe (Figure 19b). Although we do not have TEM data on the illitic fringe yet, it appears that, at $\mathrm{pH}$ $=4$, the low-F biotites alter to a dioctahedral structure. The dioctahedral structure, in turn, stabilizes K (see discussion by Fanning and Keramidas, 1977) and the K-Cu exchange is reversed. Note that $\mathrm{K}$ remains available because the flow rates were slow and that a $\mathrm{K}-\mathrm{Cu}$ exchange is still possible, because an appreciable percentage of $\mathrm{Cu}$ (relative to native copper inclusions) is present as exchangeable cations in the hydrated interlayers. Figure 20 indicates that biotite, at $\mathrm{pH}=3$, has started to dissolve from 1 to 3 weeks of reaction. Loss of $\mathrm{Cu}$ from biotite at lower $\mathrm{pH}$ values might be coupled to dissolution (more work is needed to pin this down), as was the case for high-F biotite (llton et al., in press).

\section{Comparison of low-F and high-F biotite experiments, a discussion- Copper} uptake by low-F biotites is more rapid and extensive, initially, than copper uptake by highF biotites (results for high-F biotite were given in 1991 DOE progress report and Ilton et al., in press). The relative behavior of low-F and high- $\mathrm{F}$ biotite is consistent with what we would predict based on differences in the fluorine contents of the two micas. Higher fluorine tends to retard the release of potassium to solution (see review by Fanning and 


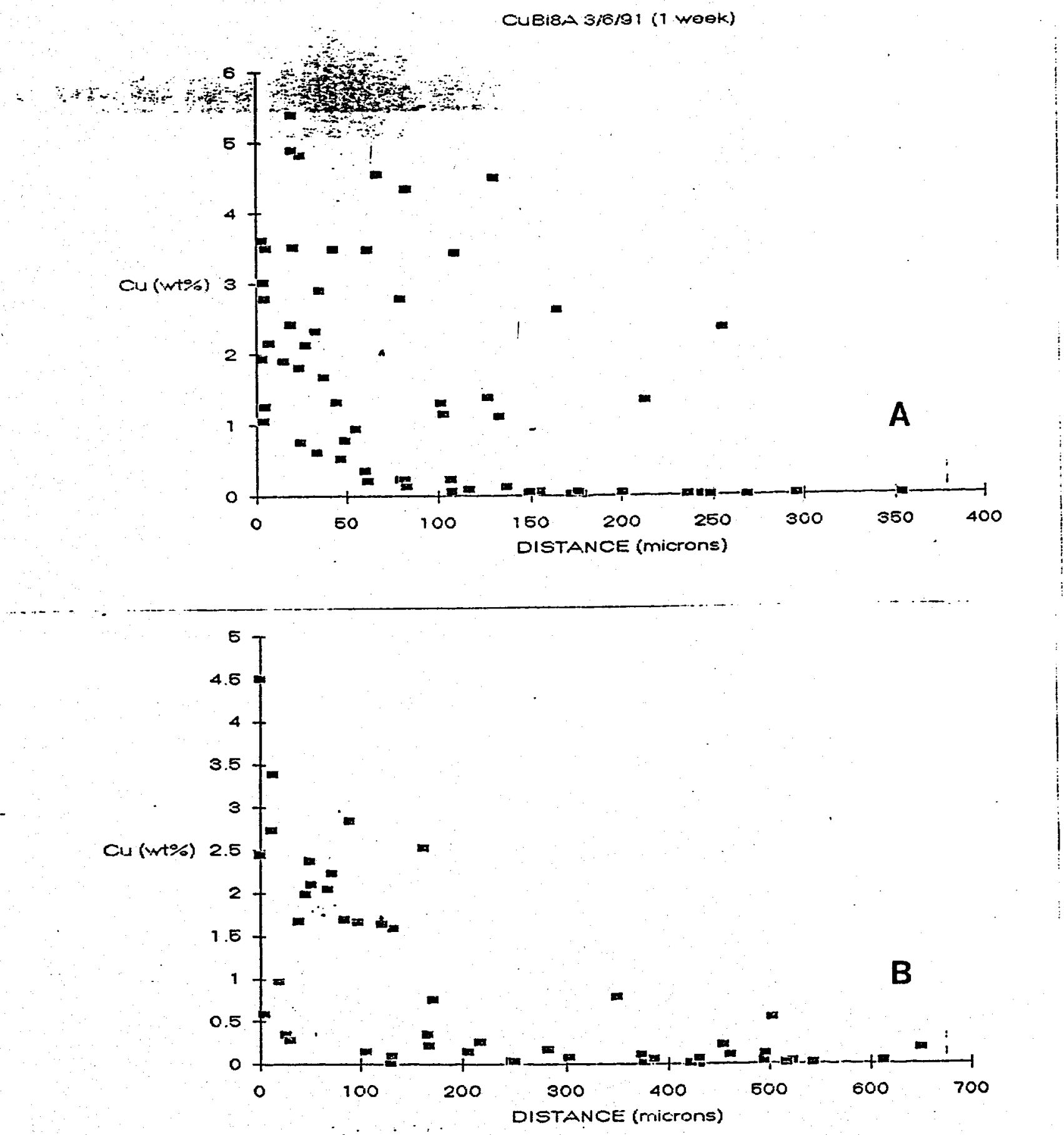

Fig. 13: Concentration of copper in a low-F biotite, that has been reacted with a copper sulfate solution at $p H=3$, as a function of distance from the edge of the mica grain: (A) 1 week experiments and (B) 3 week experiments. Note that copper concentrations decrease from 1 to 3 weeks. All analyses were obtained by elecron microprobe. 


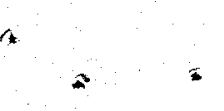
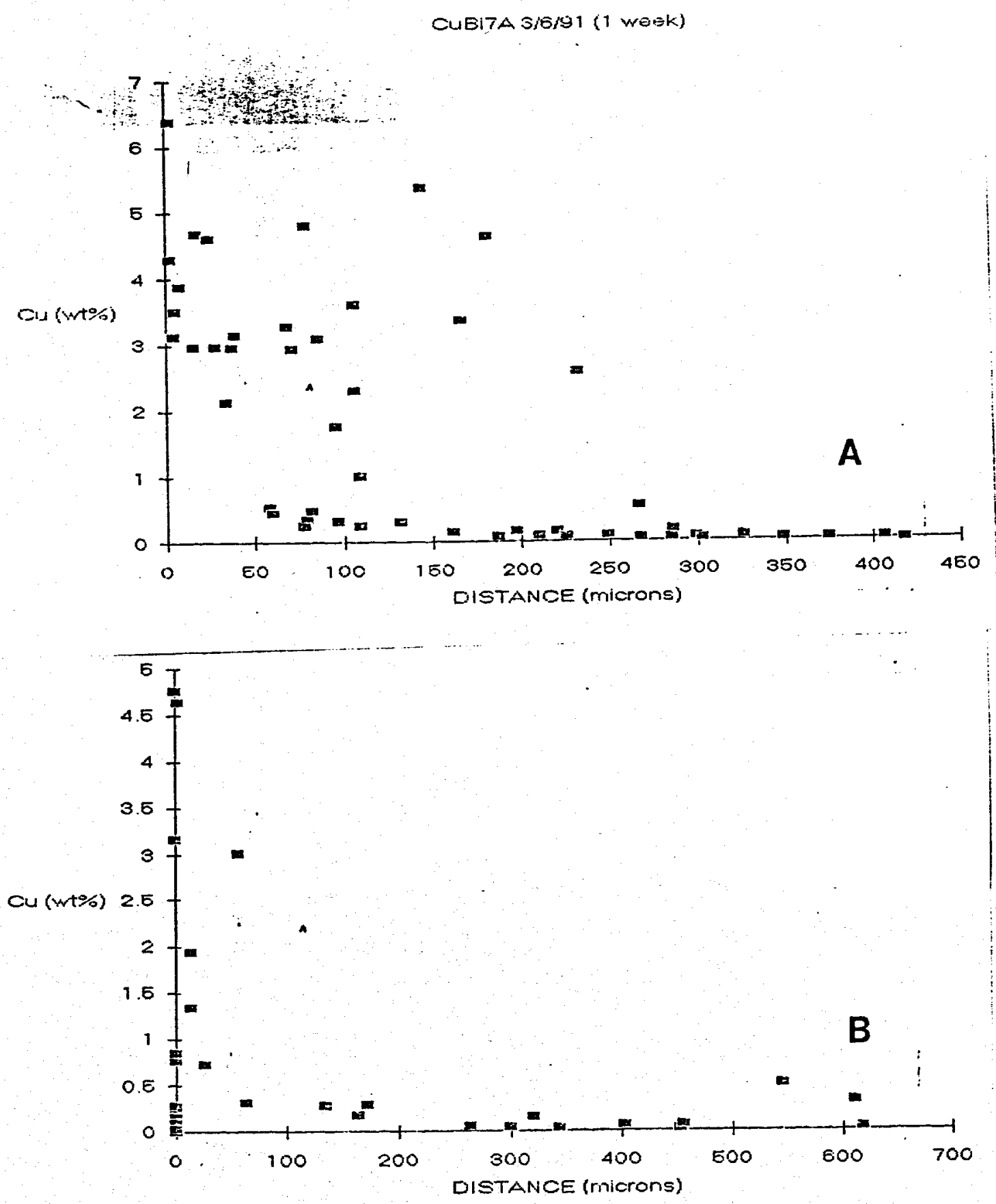

Fig. 14: Concentration of copper in a low-F biotite, that has been reacted with a copper sulfate solution at $p H=4$, as a function of distance from the edge of the mica grain: (A) 1 week experiments and (B) 3 week experiments. Note that copper concentrations decrease dramatically from 1 to 3 weeks. All analyses were obtained by elecron microprobe. 

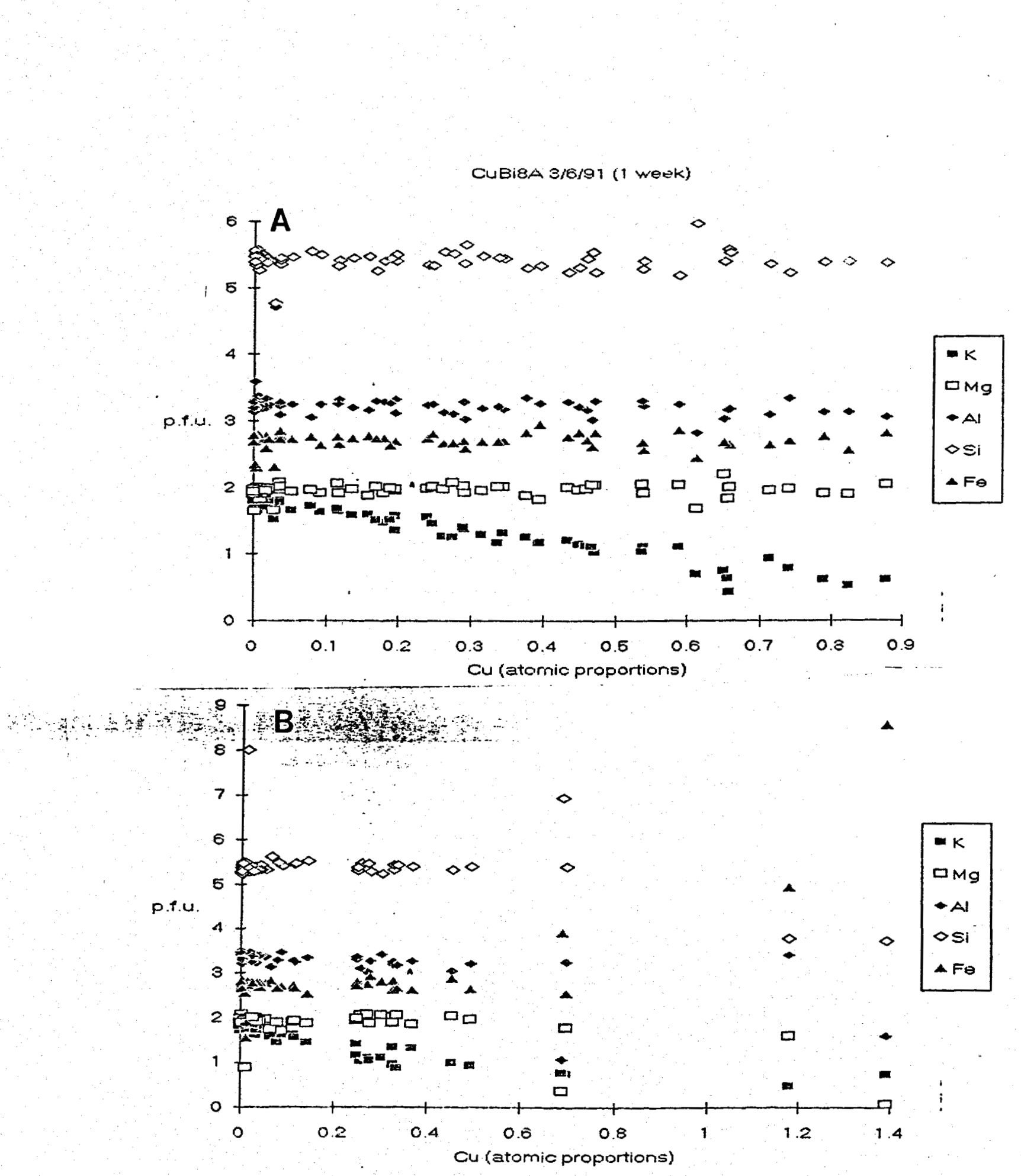

Fig. 15: $\mathrm{Plot}$ of $\mathrm{Cu}$ concentrations versus $\mathrm{K}, \mathrm{Mg}, \mathrm{Al}, \mathrm{Si}$, and $\mathrm{Fe}$ in low-F biotite reacted with copper sulfate solution, at $\mathrm{pH}=3$ : (A) 1 week experiments and (B) 3 week experiments. Note that only $\mathrm{Cu}$ and $\mathrm{K}$ are correlated. All analyses were obtained by elecron microprobe. 
CUBiTA 3/6/91 (1 woEk)

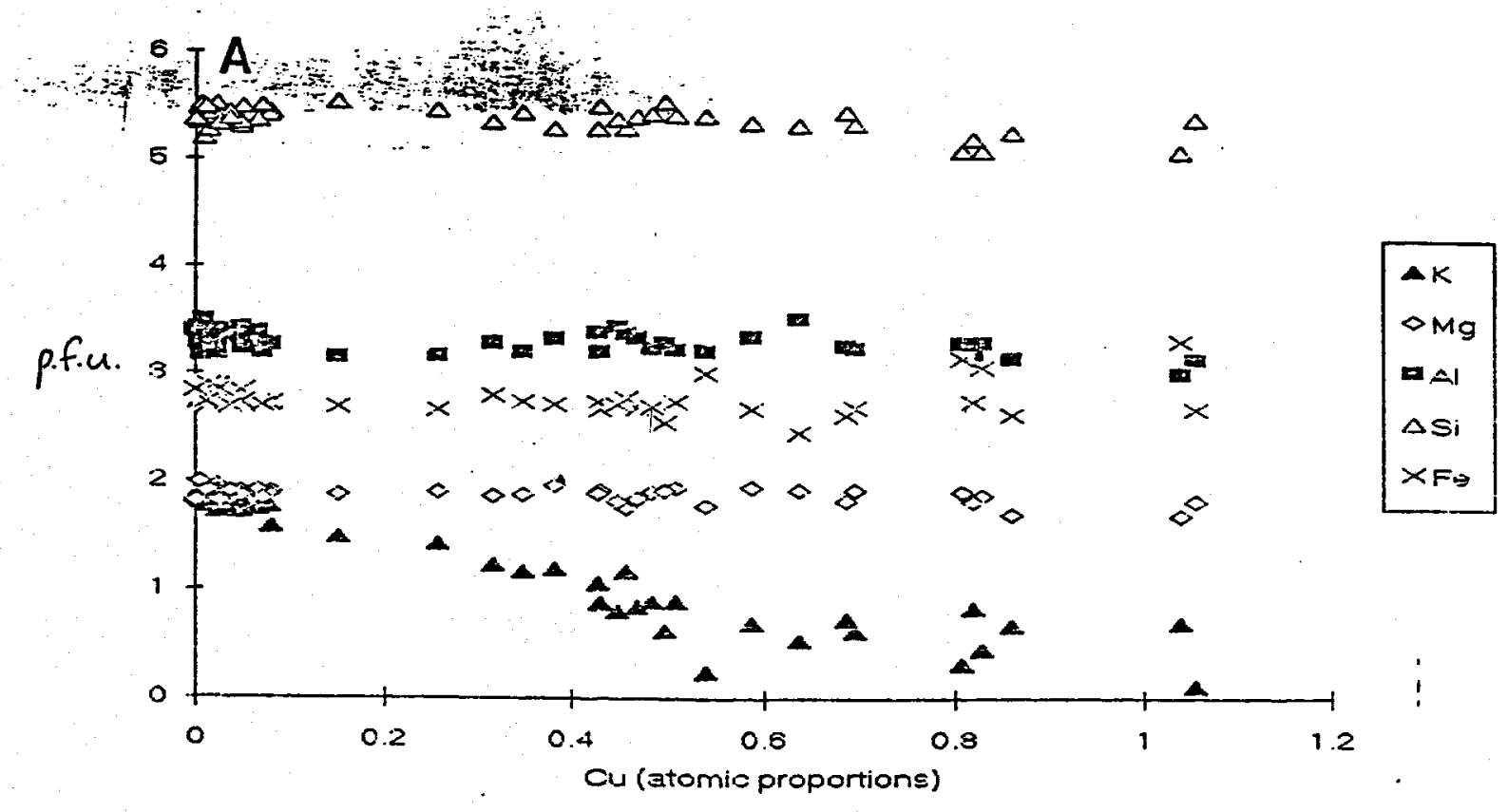

${ }^{+1}$

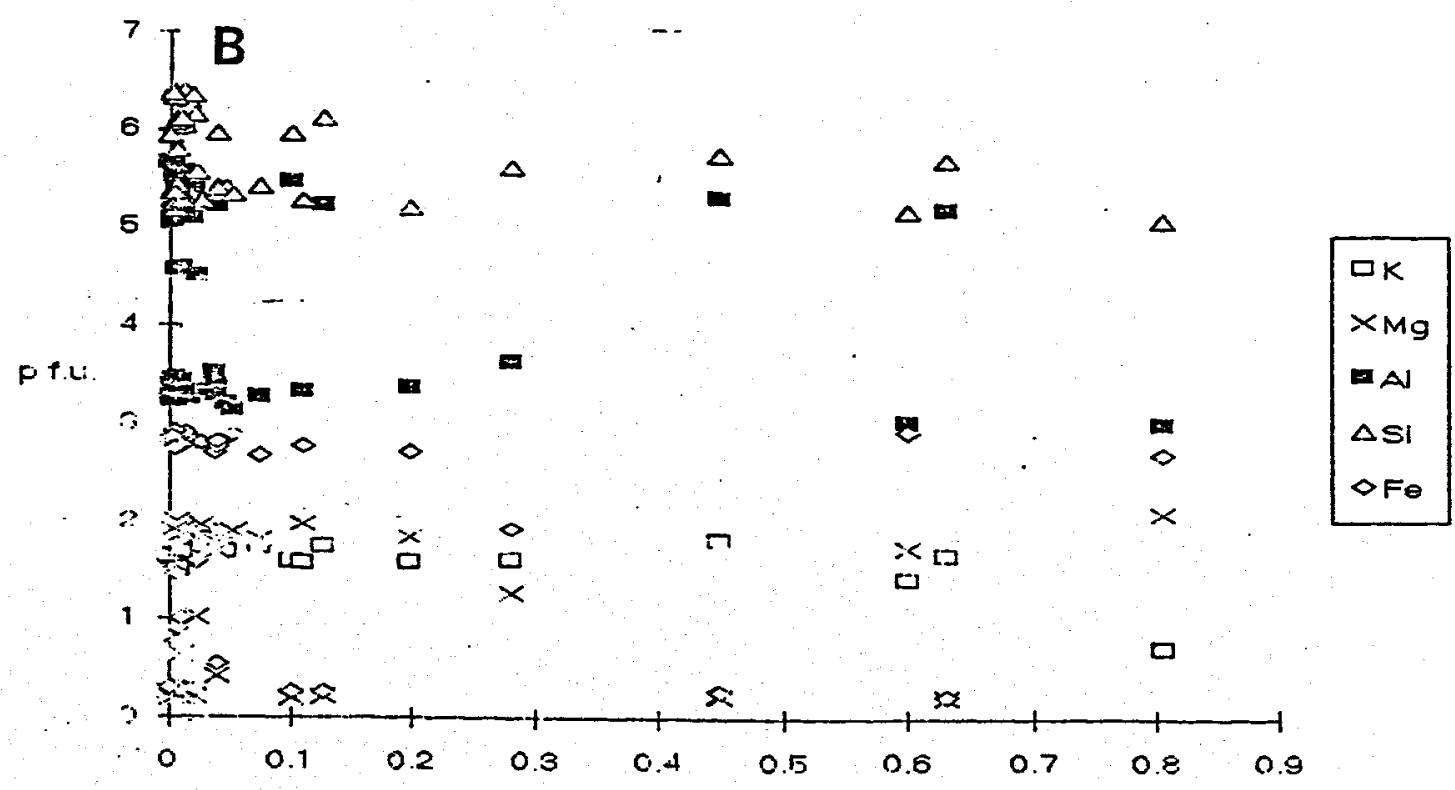

Fig. 16: Plot of $\mathrm{Cu}$ concentrations versus $\mathrm{K}, \mathrm{Mg}, \mathrm{Al}, \mathrm{Si}$, and $\mathrm{Fe}$ in low-F biotite reacted with copper sulfate solution, at $\mathrm{pH}=4$ : (A) 1 week experiments and (B) 3 week experiments. Note that only $\mathrm{Cu}$ and $\mathrm{K}$ are correlated. All analyses were obtained by elecron microprobe. * For / week experiments 


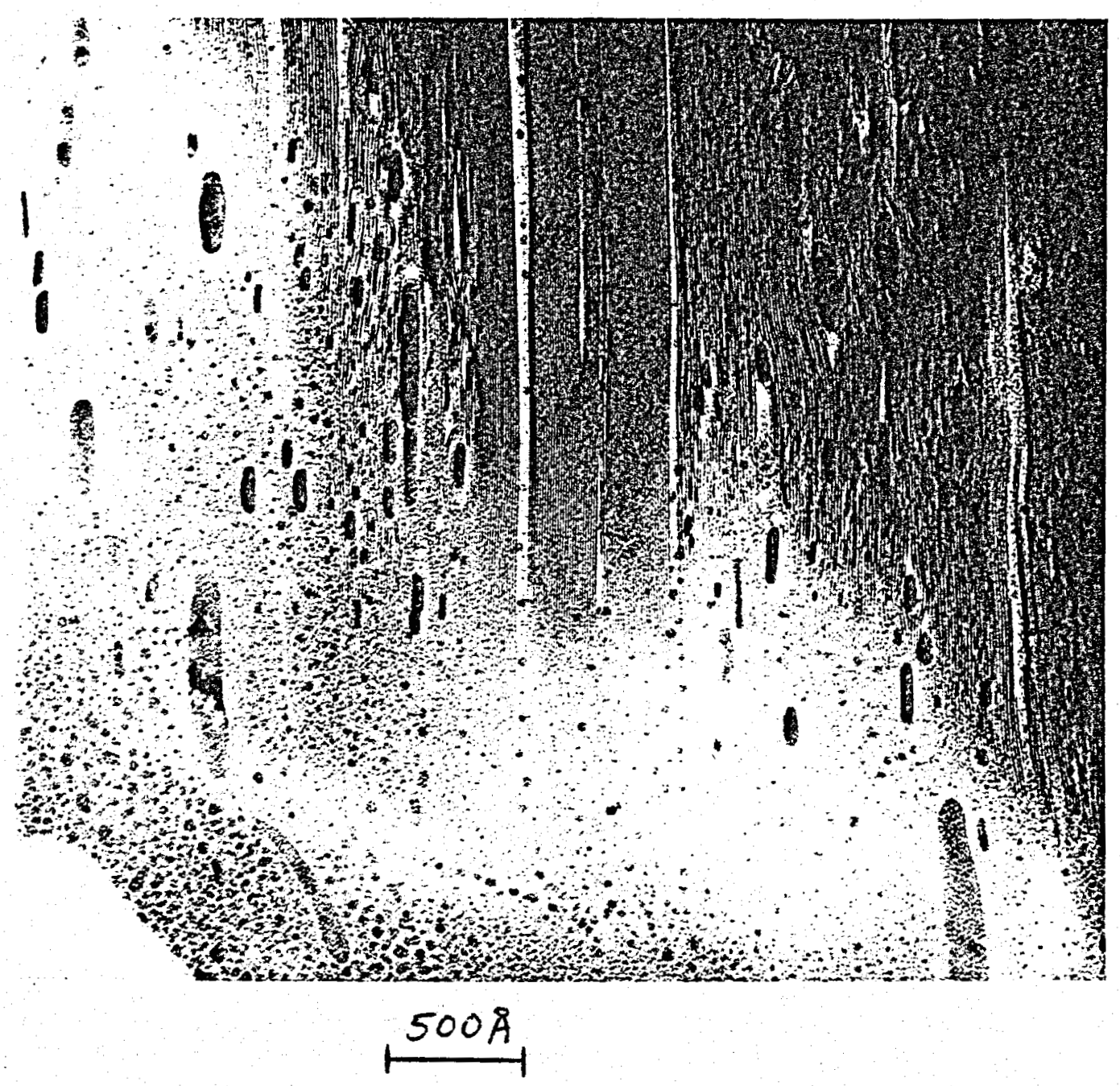

Fig. 17: TEM image, viewed perpendicular to $c^{*}$, of low-F biotite reacted with acidic-copper sulfate solution. The numerous inclusions, sandwiched between the biotite layers, are metallic copper. 


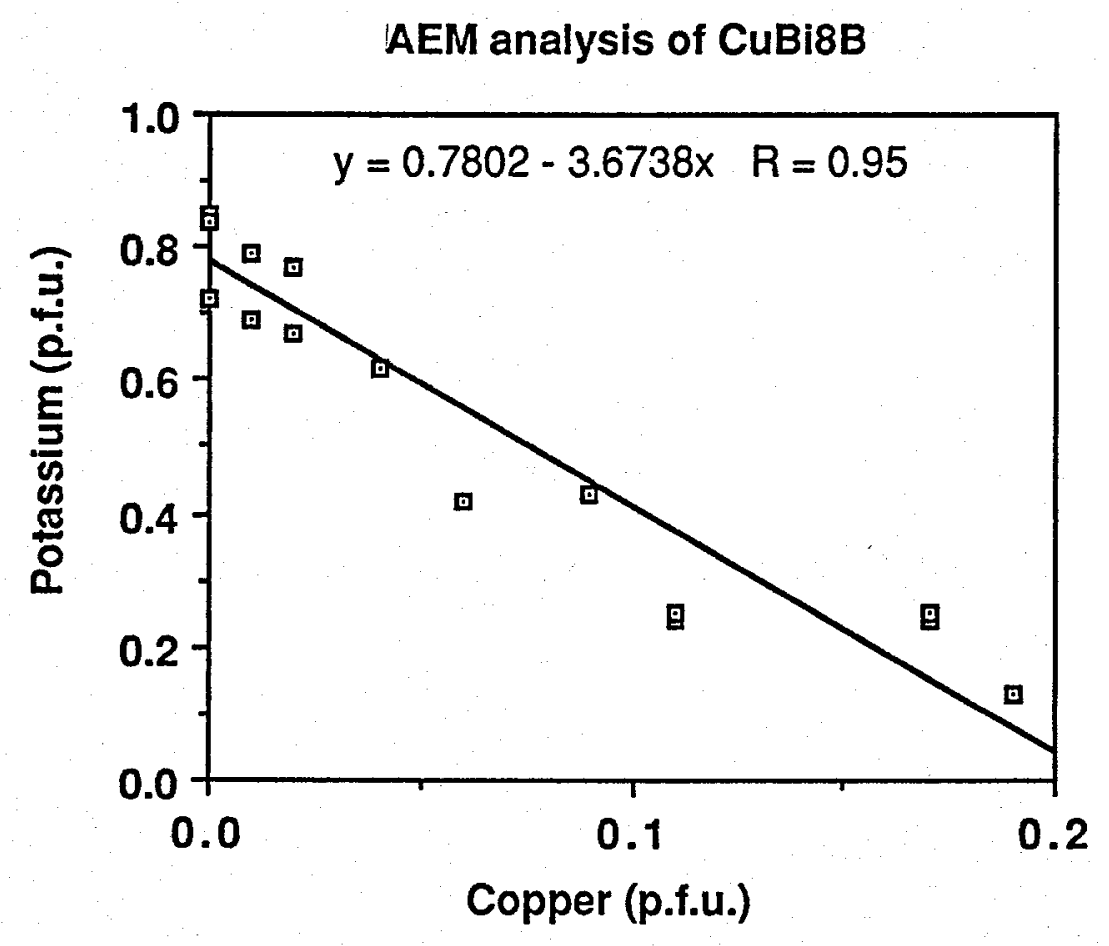

Fig. 18: Plot of AEM analyses of $\mathrm{Cu}$ and $\mathrm{K}$ in low-F biotite reacted with acidic-copper sulfate solutions. Analyses were taken in Cu-inclusion free areas. 

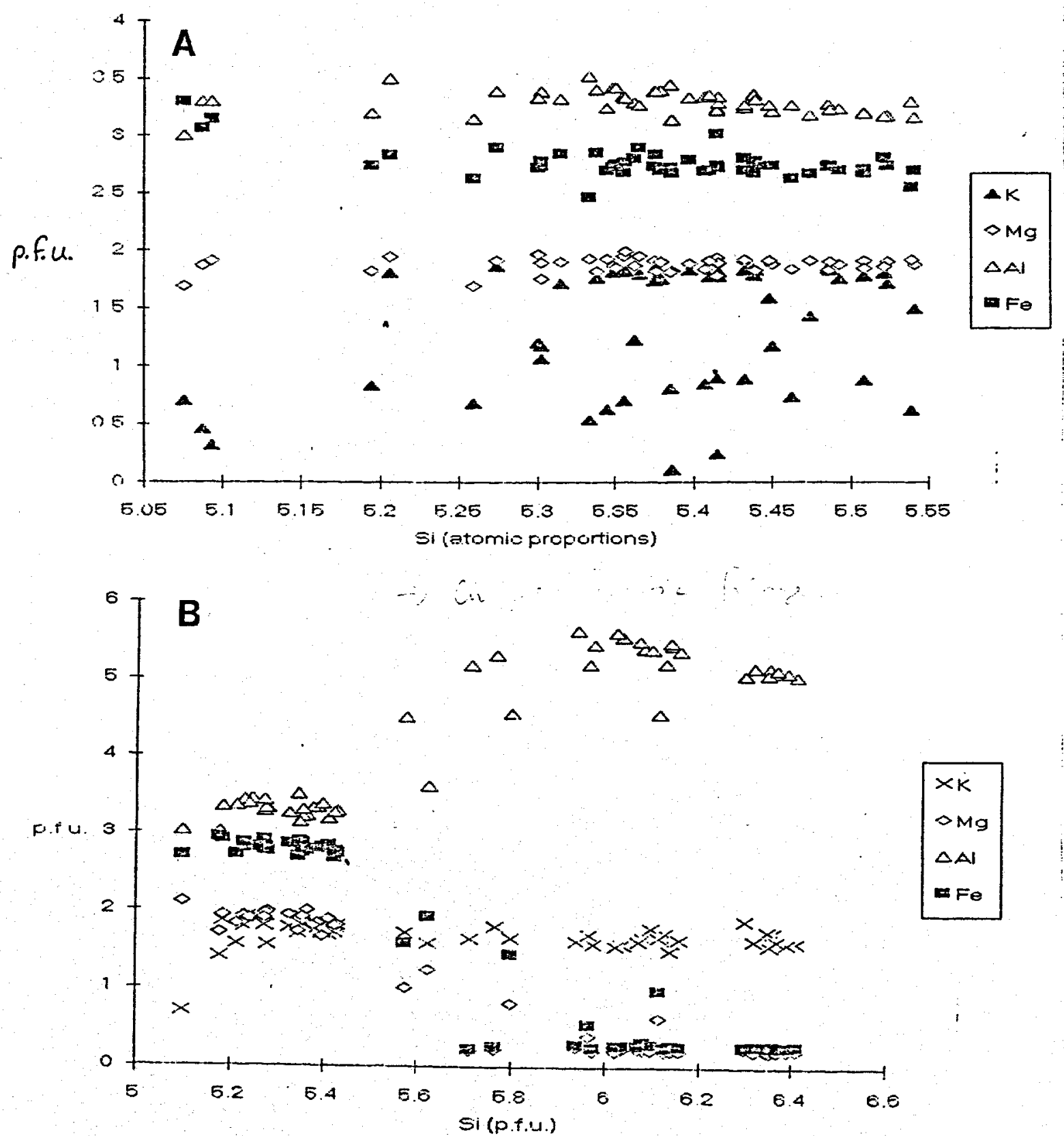

Fig. 19: Plot of $\mathrm{Si}$ concentrations versus $\mathrm{K}, \mathrm{Mg}, \mathrm{Al}$, and $\mathrm{Fe}$ in low-F biotite reacted with copper sulfate solution, at $p H=4$ : (A) 1 week experiments and (B) 3 week experiments. All analyses to the right of the vertical dashed line were taken in the illitic fringe. All analyses were obtained by elecron microprobe. 

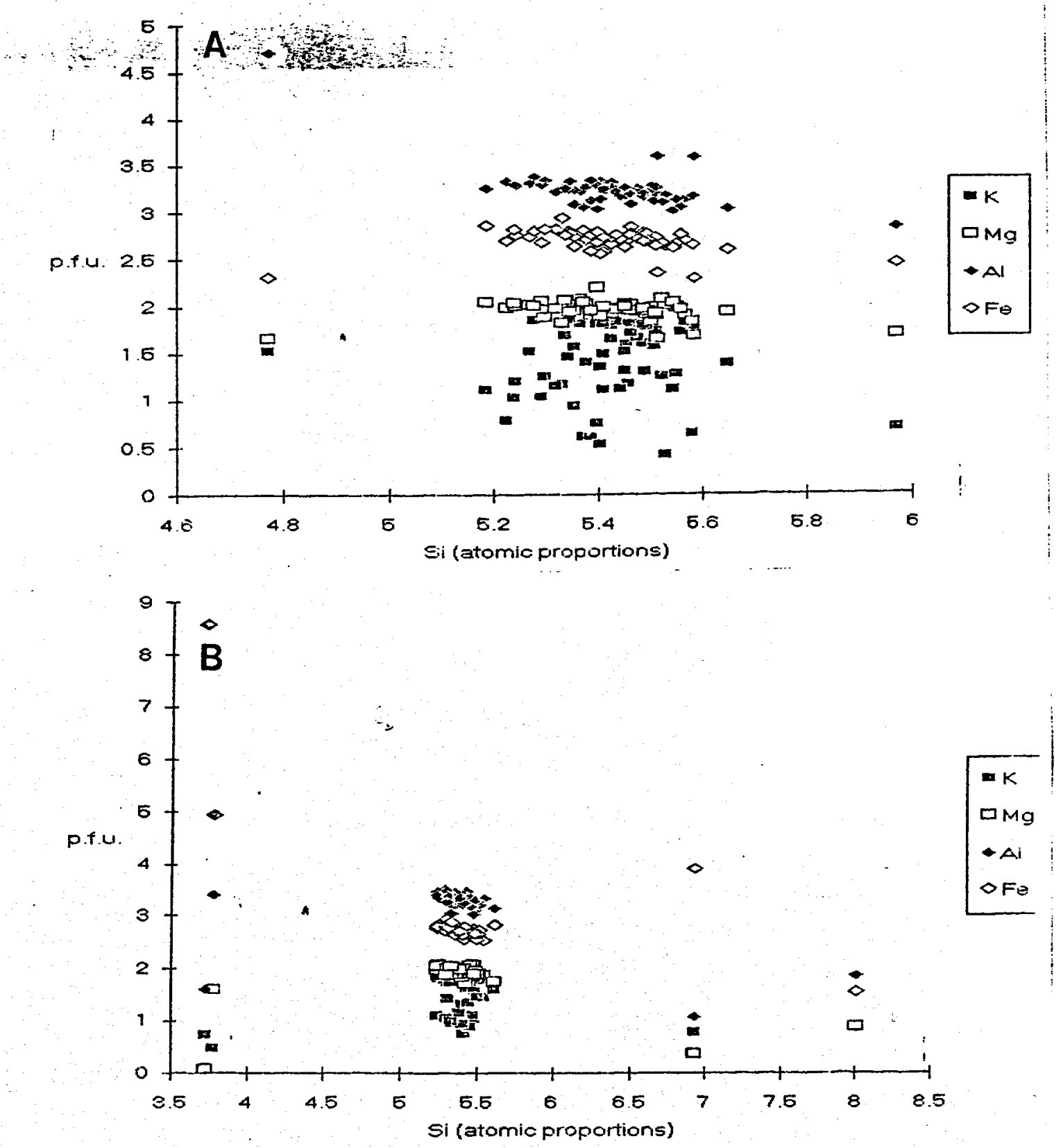

Fig. 20: Plot of Si concentrations versus $\mathrm{K}, \mathrm{Mg}, \mathrm{Al}$, and $\mathrm{Fe}$ in low-F biotite reacted with copper sulfate solution, at $p H=3$ : (A) 1 week experiments and (B) 3 week experiments. All analyses were obtained by elecron microprobe. 
Keramidas, 1977). Hoda and Hood (1972) showed that fluoritie is the strongest determinant of potassium stability in micas during weathering. Consequently, we would expect high-F biotite to retain potassium more tenaciously than low-F biotite. This, in turn, would allow low-F biotite to absorb copper more readily than high-F biotite.

The results for low- $\mathrm{F}$ biotite show that $\mathrm{Cu}$ is substituting for $\mathrm{K}$ in the interlayer sites of biotite (i.e., Figure 18 and positive correlation between $\mathrm{Cu}$ concentrations and density of expanded interlayers with no associated $\mathrm{Cu}$ inclusions), whereas the results for high-F biotite were ambiguous. In natural biotite specimens $\mathrm{Cu}$ can also substitute for $\mathrm{K}$ (Ilton and Veblen, in review).

It is important to note that comparison of TEM observations between natural and experimental assemblages indicates that the textures produced in the low-F biotite, relative to those produced in high-F biotite, are more similar to textures in copper-enriched biotites from porphyry copper systems. This is understandable because the starting compositions of the naturally occurring biotites are closer to the low-F biotite compositions.

\section{COPPER-ENRICHED FELDSPARS AND BIOTITES FROM THE CYPRUS CASA GRANDE PORPHYRY COPPER DEPOSIT: A TEM AND EMP INVESTIGATION}

This section is divided into two parts: copper-enriched (1) feldspars and (2) biotites. All of the copper-enriched specimens are from the chrysocolla zone (sample 3F 613). Feldspars from the protore are discussed briefly. Sample descriptions are given in detail by Veblen and Ilton (1991 DOE progress report) and by Ilton and Veblen (in review). The geology of the deposit is described by Cook (1988).

\section{Feldspar}


Cook (1988) notes that half the copper in the chrysocolla zone (the zone richest in $\mathrm{Cu}$ ) occurs in the altered plagioclase and biotite phenocrysts, and he presents electron microprobe (EMP) analyses for altered plagioclase phenocrysts containing up to $38 \mathrm{wt}$ \% $\mathrm{CuO}$. The purpose of this part of the project is to use transmission and analytical electron microscopy (TEM/AEM) to examine plagioclase phenocrysts from each zone and characterize the alteration reactions and products as a function of position and degree of alteration in the orebody. The primary goal of the study is to ascertain the mode of copper enrichment in plagioclase.

Initial Results- One sample, from thin section \# 3F-613 (chrysocolla zone), has been studied by TEM. Before TEM examination, the plagioclase phenocrysts were analyzed with the electron microprobe. Back-scattered electron images showed large areas of "fresh" plagioclase cross-cut by zones and pockets of alteration usually occurring along cleavage cracks and other fractures. As shown by the analyses in Table 3, the unaltered plagioclase is relatively free of copper. EMP analyses of the alteration zones in the phenocrysts showed a wide range of $\mathrm{Cu}$ concentration ranging from about 2 to $38 \mathrm{wt}$ \% $\mathrm{CuO}$. Representative probe analyses, using a $5 \mathrm{~mm}$ beam, of the altered zones are shown in Table 4 . Note that in many cases the totals are considerably less than $100 \%$. Once detailed microprobe work was completed, the same phenocrysts were prepared for TEM study by ion-milling the phenocrysts, which were supported by a $2.3 \mathrm{~mm}$ silver grid. Despite using extra care, ion-milling proved difficult due to vastly different milling rates of the host plagioclase and the alteration zones. Several of the areas examined by EMP were lost due to uneven milling, but others remained intact, and additional areas not studied by the microprobe were exposed for TEM study.

TEM examination of the alteration zones in the plagioclase phenocrysts indicate two primary hosts for copper. The first of these, which we refer to as the "mesh matrix", contains abundant $\mathrm{Cu}$-rich particles as shown in Figures 21 and 22. The copper particles range in size from a few $\AA$ to about $1.0 \mathrm{~mm}$ in diameter. The concentration of $\mathrm{Cu}$ particles in the mesh matrix is so high that obtaining a selected-area electron diffraction (SAED) pattern using a large 
aperture resulted in a polycrystalline ring pattern (Fig. 23). Indexing of this pattern indicated that the $\mathrm{Cu}$-phase is native copper. This diffraction pattern also shows that the copper crystals have no preferred orientation with respect to the supporting matrix. The matrix material itself is amorphous, showing no diffraction spots. When tilting the specimen it was evident that the matrix was indeed a three-dimensional network of small amorphous laths, interconnected into a complex mesh. Everywhere this mesh was observed, it was choked with copper crystals. It is unclear at this stage of the research whether the copper precipitation occurred at the same time as the mesh was forming, or was deposited into the already-formed matrix. Analytical electron microscopy data on these areas will be discussed below.

The second mode of occurrence for native copper crystals consisted of a smectite-like matrix, as shown in Figures 24 and 25. In contrast to the mesh matrix, the smectite-like matrix is much more characteristic of a normal sheet silicate, including many examples of typical "ballsmectite" (Fig. 24). SAED patterns of this matrix showed basal reflections characteristic of smectite. The copper inclusions occur as smeared out platelets that can reach considerable size (Fig. 24), or as lozenge shaped discs that form between the layers of the sheet silicate (Fig. 25), very similar to the occurrence of native copper bullets between the layers in $\mathrm{Cu}$-rich biotites, described by Ilton and Veblen (1988). High-resolution TEM images of the smectite sometimes showed lattice fringes characteristic of sheet silicates (Fig. 25) although the material damaged very quickly under the electron beam.

Representative AEM analyses for these altered areas are shown in Table 5. For the mesh matrix areas, bulk AEM analyses were obtained by rastering a large diffuse beam over the entire area (first three analyses in Table 5). These bulk compositions were very rich in $\mathrm{Cu}$ and appear to correspond to the most $\mathrm{Cu}$-rich alteration zones observed in backscattered electron images obtained on the microprobe (compare analysis \#1, Table 4). Using the smallest beam size, we tried to collect compositional data for the mesh matrix itself (analyses 4 and 5, Table 5). The copper crystals were so ubiquitous, however, that we were unable to get a "clean" analysis of the matrix. As shown in Table 5, the matrix is rich in $\mathrm{SiO}_{2}$, and also contains 
Table 3. Representative electron microprobe (EMP) analyses of plagioclase phenocrysts from the chrysocolla zone.

\begin{tabular}{ccccc}
\hline analysis number & 1 & 2 & 3 & 4 \\
\hline & & & & \\
$\mathrm{SiO}_{2}$ & 59.29 & 57.64 & 57.45 & 57.89 \\
$\mathrm{Al}_{2} \mathrm{O}_{3}$ & 26.06 & 26.22 & 26.55 & 25.83 \\
$\mathrm{Na}_{2} \mathrm{O}$ & 6.01 & 6.37 & 6.29 & 6.53 \\
$\mathrm{CaO}$ & 7.51 & 8.32 & 8.59 & 7.94 \\
$\mathrm{~K}_{2} \mathrm{O}$ & 0.50 & 0.46 & 0.41 & 0.48 \\
$\mathrm{MgO}$ & 0.03 & 0.02 & 0.00 & 0.02 \\
$\mathrm{FeO}$ & 0.17 & 0.18 & 0.17 & 0.20 \\
$\mathrm{MnO}$ & 0.00 & 0.06 & 0.00 & 0.00 \\
$\mathrm{CuO}$ & 0.07 & 0.00 & 0.08 & 0.09 \\
$\mathrm{SO}$ & 0.00 & 0.01 & 0.01 & 0.00 \\
\hline Total & 99.64 & 99.28 & 99.55 & 98.97
\end{tabular}

Plagioclase formula: based on normalization to eight oxygens

\begin{tabular}{ccccc}
$\mathrm{Si}$ & 2.65 & 2.6 & 2.59 & 2.62 \\
$\mathrm{Al}$ & 1.37 & 1.4 & 1.41 & 1.38 \\
\hline total T site & 4.02 & 4.00 & 4.00 & 4.00 \\
& & & & \\
$\mathrm{Na}$ & 0.52 & 0.56 & 0.56 & 0.57 \\
$\mathrm{Ca}$ & 0.36 & 0.40 & 0.41 & 0.39 \\
$\mathrm{~K}$ & 0.03 & 0.03 & 0.02 & 0.03 \\
$\mathrm{Fe}$ & 0.01 & 0.01 & 0.01 & 0.01 \\
\hline Total interstitial & 0.92 & 1.00 & 1.00 & 1.00
\end{tabular}


Table 4. Representative electron microprobe (EMP) analyses of alteration zones in plagioclase phenocrysts from the chrysocolla zone.

\begin{tabular}{ccccccc}
\hline analysis number & 1 & 2 & 3 & 4 & 5 & 6 \\
\hline & & & & & & \\
$\mathrm{SiO}_{2}$ & 36.27 & 32.79 & 46.66 & 40.62 & 51.50 & 49.33 \\
$\mathrm{Al}_{2} \mathrm{O}_{3}$ & 5.65 & 10.01 & 26.79 & 21.88 & 28.88 & 21.66 \\
$\mathrm{Na}_{2} \mathrm{O}$ & 0.23 & 0.06 & 0.07 & 0.10 & 6.34 & 4.47 \\
$\mathrm{CaO}$ & 2.36 & 1.75 & 0.95 & 1.04 & 4.26 & 7.80 \\
$\mathrm{~K} 2 \mathrm{O}$ & 0.14 & 0.12 & 0.06 & 0.09 & 0.34 & 0.34 \\
$\mathrm{MgO}$ & 0.35 & 0.38 & 0.50 & 0.44 & 0.09 & 0.05 \\
$\mathrm{FeO}$ & 0.21 & 1.02 & 3.71 & 3.57 & 0.27 & 0.25 \\
$\mathrm{MnO}$ & 0.05 & 0.02 & 0.01 & 0.00 & 0.00 & 0.00 \\
$\mathrm{CuO}$ & 27.34 & 24.12 & 10.22 & 15.43 & 4.64 & 2.95 \\
$\mathrm{SO} 3$ & 0.23 & 0.21 & 0.08 & 0.11 & 0.04 & 0.05 \\
\hline $\mathrm{Total}$ & 72.83 & 70.48 & 89.05 & 83.29 & 96.37 & 86.90
\end{tabular}




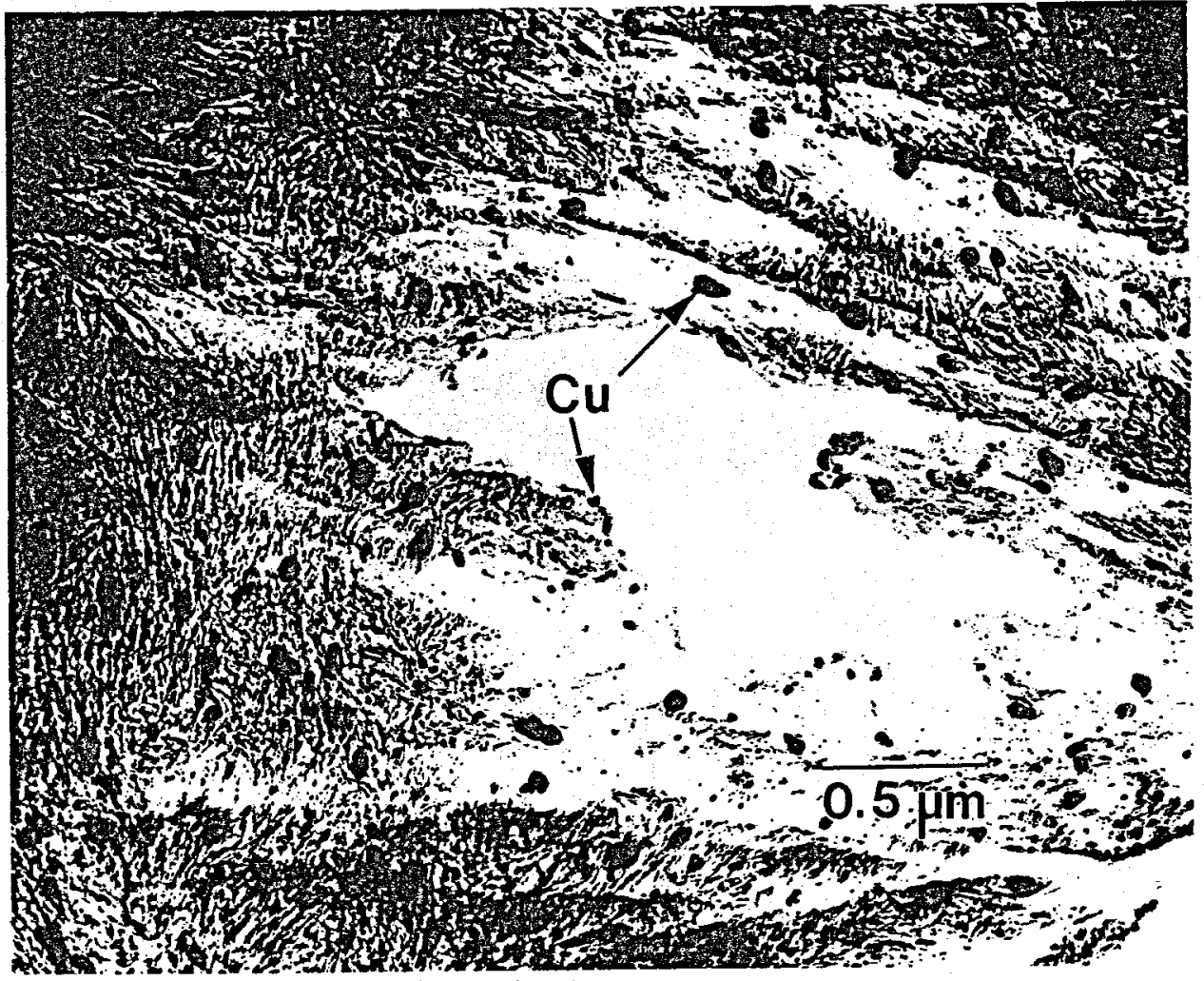

Fig. 21: Low-magnification bright-field TEM image of alteration zone in plagioclase phenocrysts from the chrysocolla zone. The abundant native copper crystals are supported by a three-dimensional amorphous mesh matrix. 


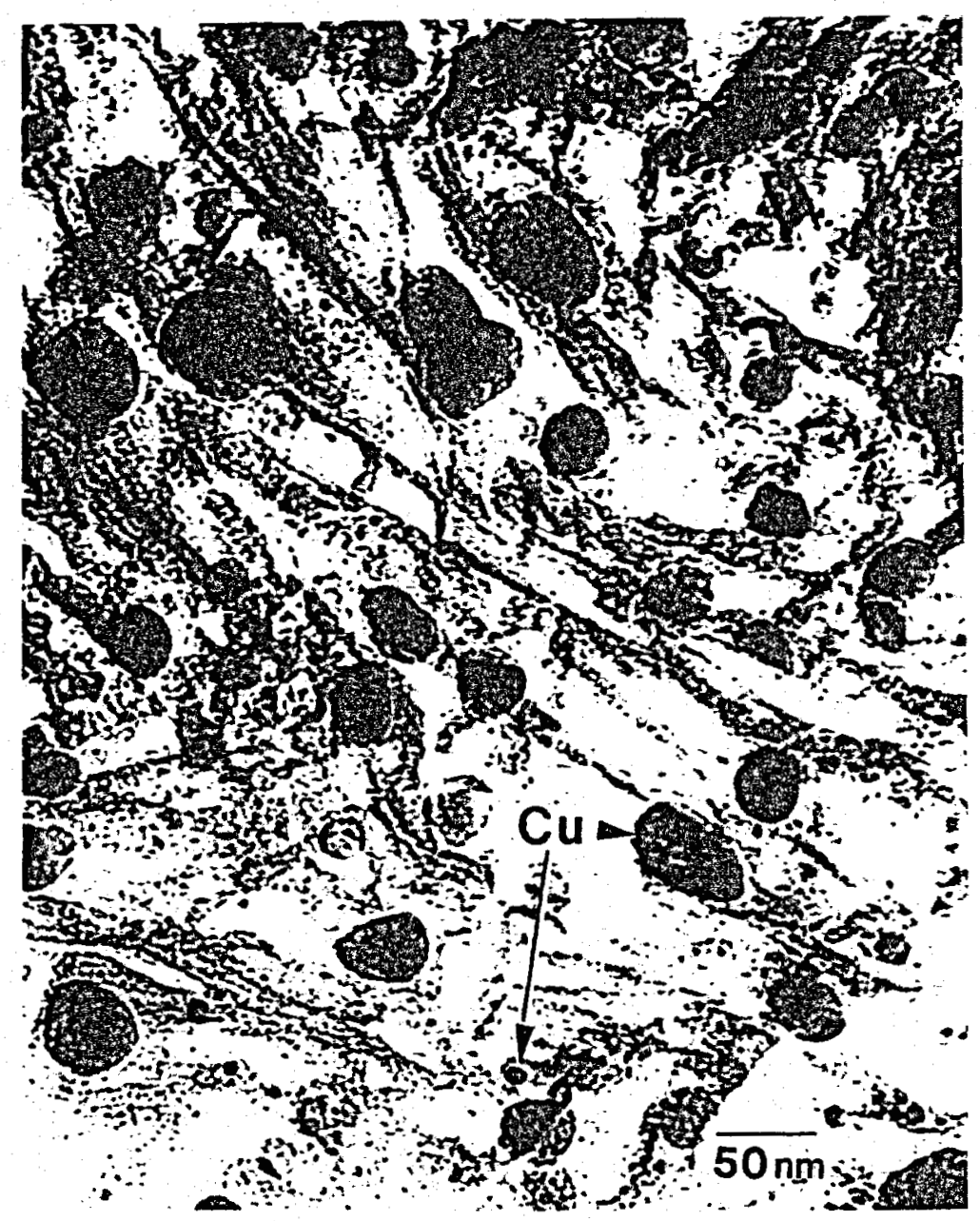

Fig. 22: High-magnification bright-field TEM image of the mesh matrix full of copper crystals. The copper crystals span a wide size range are do not occur in any special crystallographic orientation with respect to the mesh matrix. 


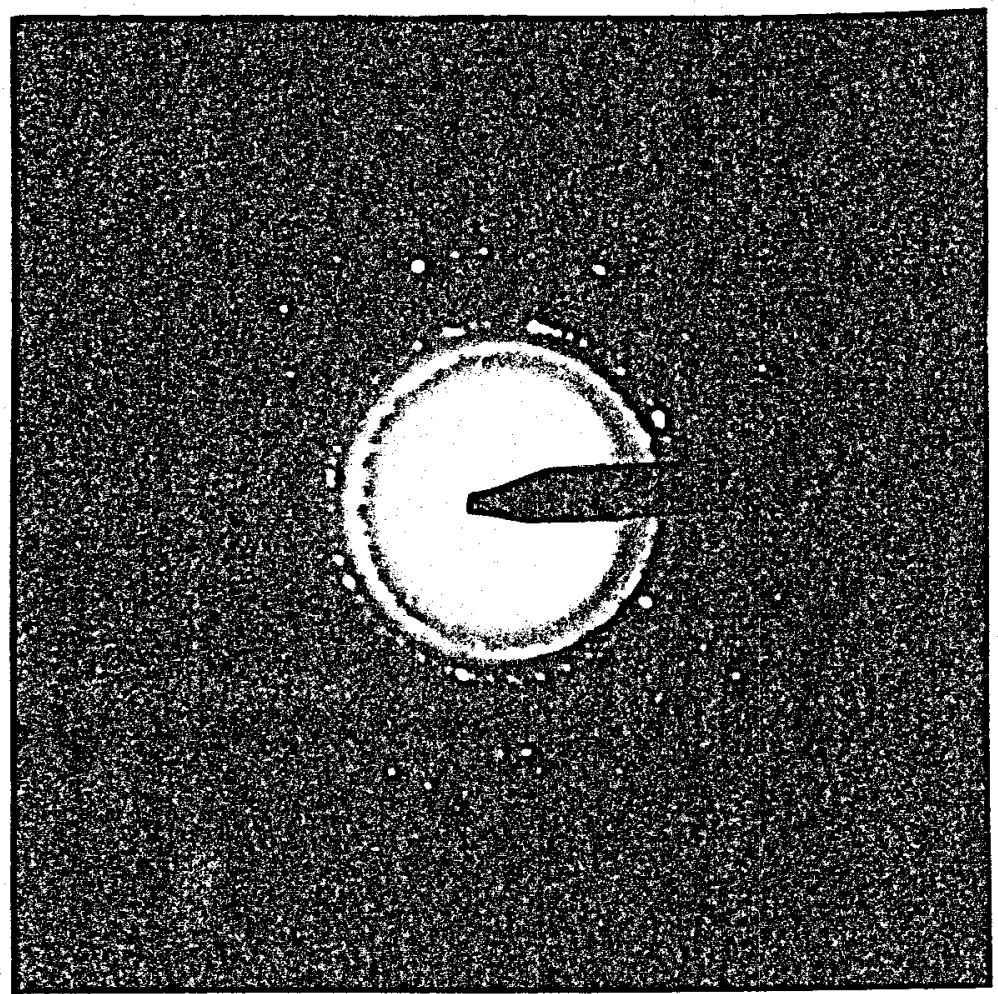

Fig. 23: Selected-area electron diffraction (SAED) pattern taken of the mesh plus copper areas using a large aperture. The abundant, randomly-oriented copper crystals lead to a polycrystalline ring pattern which is indexed native copper. The first four rings are indexed as follows: (1) $\mathrm{d}_{111}=2.13 \AA$; (2) $\mathrm{d}_{200}=1.83 \AA$; (3) $\mathrm{d}_{202}=1.29 \AA ;(4) \mathrm{d}_{113}=1.09 \AA$. 


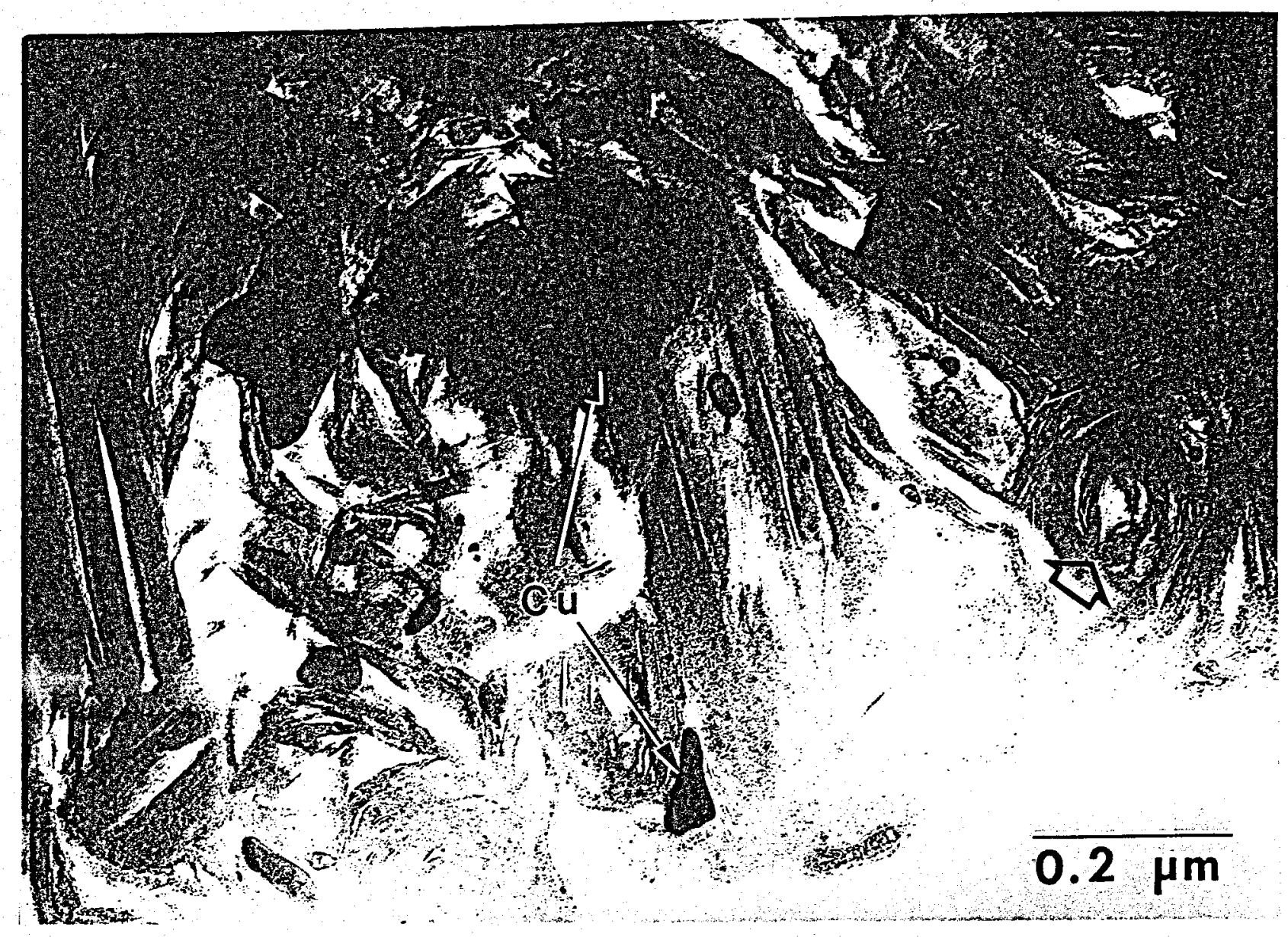

Fig. 24: Bright-field TEM image of smectite matrix containing copper inclusions. The copper seems to occur as platelets that can reach rather large dimensions. The smectite occurs as sub-parallel sheafs, or in balls as indicated by the large hollow arrow. 


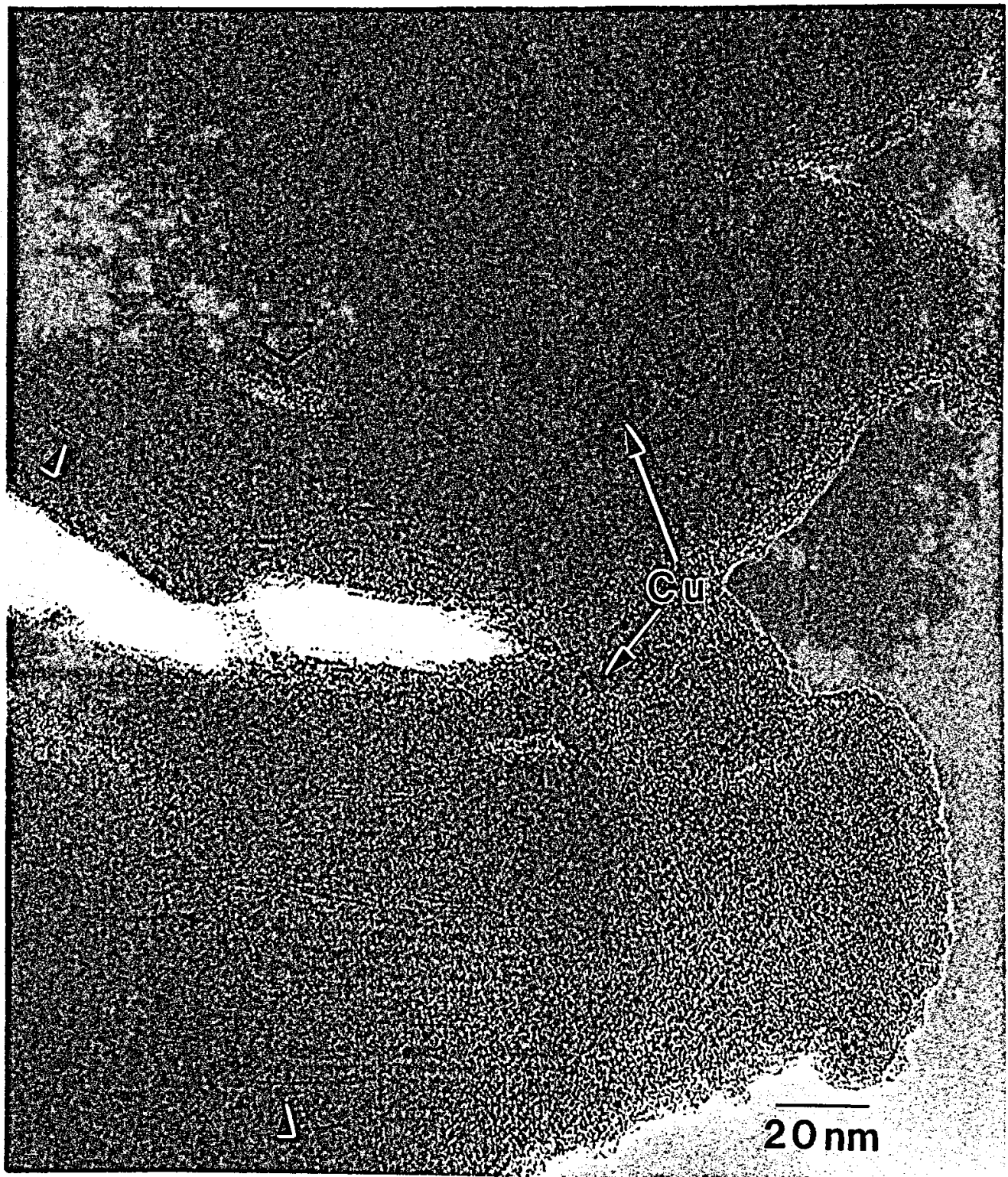

Fig. 25: High-resolution TEM image of smectite matrix with copper inclusions. Some of the smectite areas are still crystalline and show (001) lattice fringes (see arrows). The large copper inclusion occurs as a "bullet" between the expanded interlayers. The large hollow arrow points out an area of negative relief which may have contained a copper inclusion before sample preparation. The smectite damaged quickly under the electron beam. 
Table 5. Representative analytical electron microscope (AEM)* analyses of alteration zones in plagioclase phenocrysts from the chrysocolla zone**.

\begin{tabular}{cccccccccc}
\hline analysis \# & 1 & 2 & 3 & 4 & 5 & 6 & 7 & 8 \\
\hline area & Bulk & Bulk & Bulk & Mesh & Mesh & Smect. & Smect. & Smect. \\
\hline & & & & & & & & \\
$\mathrm{SiO}_{2}$ & 47.57 & 47.98 & 44.47 & 59.88 & 73.11 & 61.54 & 60.69 & 57.35 \\
$\mathrm{Al}_{2} \mathrm{O}_{3}$ & 6.98 & 7.91 & 7.69 & 11.09 & 7.58 & 30.32 & 33.46 & 34.18 \\
$\mathrm{Na}_{2} \mathrm{O}$ & 5.23 & 7.91 & 9.39 & 9.20 & 2.18 & 0.78 & 0.77 & 1.02 \\
$\mathrm{CaO}$ & 3.94 & 3.84 & 2.17 & 5.43 & 5.95 & 0.92 & 0.63 & 0.79 \\
$\mathrm{~K} 2 \mathrm{O}$ & 0.39 & 0.27 & 0.91 & 0.42 & 0.27 & 0.19 & 0.12 & 0.18 \\
$\mathrm{MgO}$ & 0.98 & 0.31 & 0.49 & 0.00 & 0.00 & 1.81 & 1.55 & 1.42 \\
$\mathrm{FeO}$ & 0.52 & 0.49 & 0.61 & 0.38 & 1.44 & 3.73 & 2.61 & 4.56 \\
$\mathrm{MnO}$ & 0.00 & 0.00 & 0.06 & 0.00 & 0.79 & 0.03 & 0.00 & 0.04 \\
$\mathrm{CuO}$ & 31.59 & 28.20 & 29.90 & 9.00 & 7.12 & 0.55 & 0.17 & 0.40 \\
$\mathrm{SO}{ }_{3}$ & 2.80 & 3.10 & 4.26 & 4.42 & 0.57 & 0.07 & 0.00 & 0.05 \\
\hline Total & 100.00 & 100.00 & 100.00 & 100.00 & 100.00 & 100.00 & 100.00 & 100.00 \\
* AEM analyses are standardless and are normalized to $100 \%$. & & \\
** Analyses 1 through 3 are bulk AEM data from mesh matrix plus copper; Anal. 4 and 5 \\
are from individual laths in the mesh matrix; Analyses 6 through 8 are of the smectite \\
matrix.
\end{tabular}




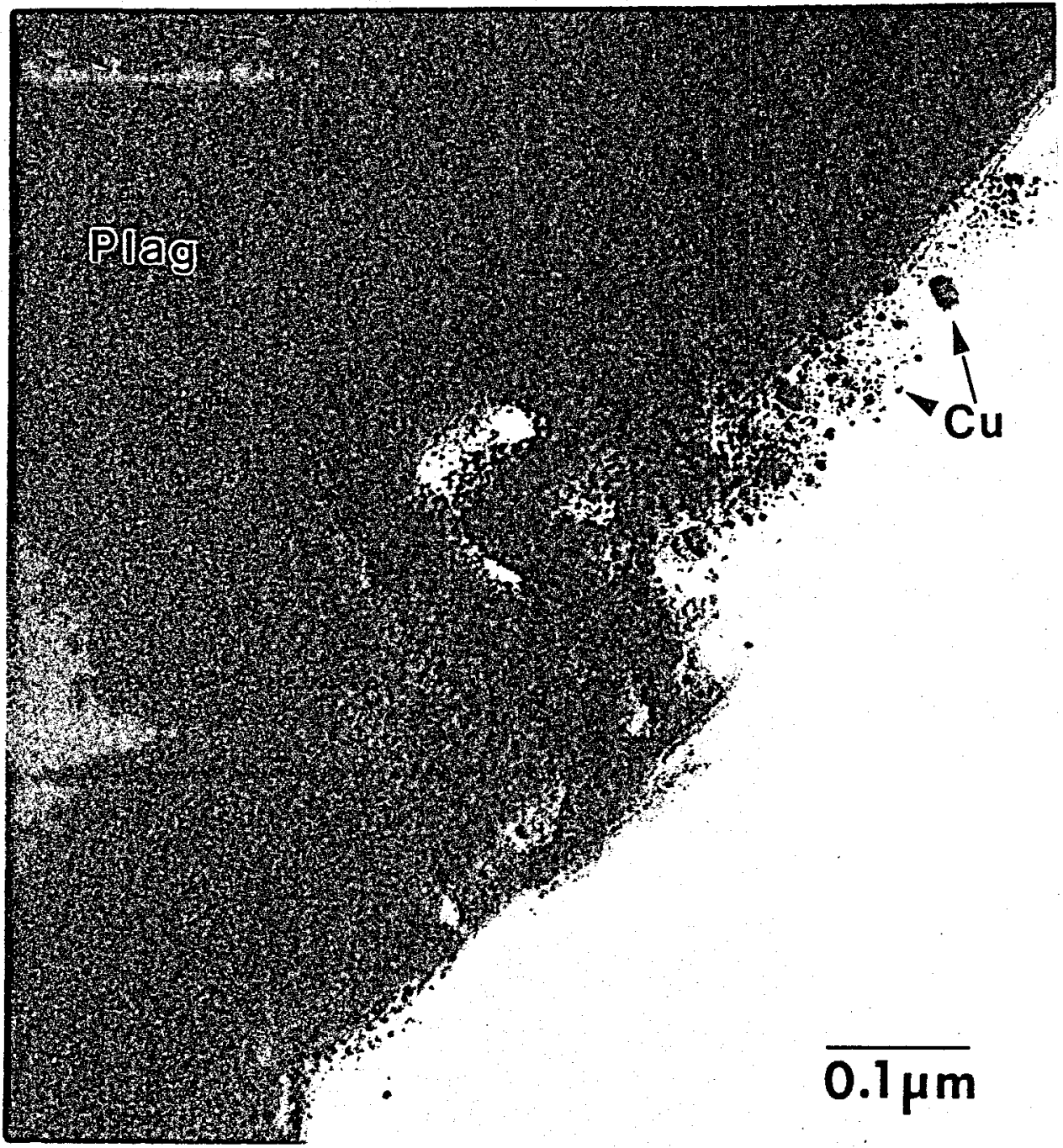

Fig. 26: Bright-field TEM image showing what appears to be a direct attack on the fresh plagioclase by the mesh matrix alteration. The alteration area is rich in copper inclusions. AEM shows that very little $\mathrm{Cu}$ is actually present in the plagioclase itself, but is abundant in the altered area. 
significant $\mathrm{Al}_{2} \mathrm{O}_{3}, \mathrm{Na}_{2} \mathrm{O}, \mathrm{CaO}$, and small amounts of $\mathrm{FeO}$. This composition is consistent with alteration of the parent plagioclase, although the exact alteration reactions, and elemental concentrations lost or gained during these reactons have yet to be determined. Some areas examined in the TEM showed evidence for the host plagioclase reacting directly to the mesh matrix plus copper, as illustrated in Figure 26. In this image it appears that the plagioclase is being attacked and replaced by mesh material, which contains many copper crystals. AEM of the unaltered plagioclase crystals revealed very low concentrations of $\mathrm{Cu}$, suggesting that very little, if any, $\mathrm{Cu}$ is actually incorporated into the plagioclase structure. Further study of these samples should elucidate the nature of the alteration reactions.

Because the copper concentration in the smectite-like areas is lower, it was possible to obtain relatively $\mathrm{Cu}$-free analyses of the smectite host (Table 5, analyses 6 through 8). These analyses show $\mathrm{SiO}_{2}, \mathrm{Al}_{2} \mathrm{O}_{3}, \mathrm{Na}_{2} \mathrm{O}$, and $\mathrm{CaO}$ contents consistent with smectite, but also show considerable amounts of $\mathrm{FeO}$.

Discussion- In the protore, plagioclase and its alteration products (mainly sericite) are essentially free of copper. It seems likely that the alteration domains in the protore plagioclase were the sites for supergene alteration and copper enrichment in plagioclases from the chrysocolla and goethite zones. From Figure 26, however, it appears that there may be some direct replacement of the fresh plagioclase by a $\mathrm{Cu}$-rich alteration product.

The results presented here show two distinct alteration hosts for the native copper crystals in the chrysocolla zone plagioclase phenocrysts. The mesh matrix is significantly richer in Cu crystals and is amorphous compared to the smectite matrix. The details of the alteration reactions are not yet worked out; it is unclear how the smectite matrix areas are related to the mesh matrix areas. 


\section{Biotite from the Chrysocolla zone, revisited}

We have made a number of new and interesting observations concerning copperenriched biotites from the chrysocolla zone. These observations were not reported in our DOE progress report for 1991. They have been incorporated recently into a paper (Ilton and Veblen, in review).

The style and degree of copper enrichment in biotite from the chrysocolla zones appear to depend on the proximity of the biotite grain to sulfide minerals. Figure 27 is a SEM micrograph of biotite that probably was once intimately intergrown with sulfides. The former sulfide inclusions are now represented by clots composed of copper-enriched iron oxyhydroxides and chrysocolla (indicated by the arrow in Figure 27). These clots are associated with a chlorite vein that bisects the biotite flake. The microprobe data indicate that "biotite," chlorite, and clays in both biotite and chlorite are copper-rich. A triangular $\mathrm{Al}-\mathrm{Si}-\mathrm{Cu}$ plot of the microprobe data (Fig. 28a) is similar to Figure 6c in Cook (1988).

We were able to ion mill the specimen pictured in Figure 27, such that our TEM observations are representative of the area shown in this figure. Triangular plots of the AEM analyses are given in Figures $28 \mathrm{a}$ and 28b. TEM observations show that this biotite specimen displays a wide range of copper enrichment styles. Figure 29 shows an area with a high concentration of expanded interlayers; copper concentrations in areas with this density of expanded interlayers commonly yield $\sim 3.5 \mathrm{wt}$. $\% \mathrm{CuO}$ by AEM. Note also the appearance of a mixed-layer sheet silicate (alternating biotite and vermiculite-like layers) between the arrows in Figure 29. Such alteration was documented by Ilton and Veblen (1988) and in Banfield and Eggleton's (1988) TEM study of biotite weathering. There is an obvious correlation between the density of expanded interlayers and the concentration of copper; increasing copper concentrations are positively correlated with an increasing density of expanded interlayers. Copper was not detected (less than $1000 \mathrm{ppm}$ ) in areas of biotite without expanded interlayers. This suggests that copper is incorporated in the interlayer region of biotite. AEM analyses of biotite with a variable density of expanded interlayers are plotted in Figure $28 \mathrm{~b}$ and tend to 
bridge the compositional gap shown by the microprobe analyses plotted in Figure 28a. This compositional gap is also shown by the microprobe analyses of biotite plotted in Figure 6c from Cook (1988). The increasing $\mathrm{Al} / \mathrm{Si}$ ratios of biotite are correlated with an increasing density of expanded interlayers and increasing copper concentrations. These observations are consistent with copper enrichment in biotite being intimately associated with the alteration of biotite to vermiculite. The greater spread in the AEM analyses of relatively unaltered biotite compared to the microprobe analyses indicates that the microprobe data reflect averaged compositions.

Figure 30 illustrates another common feature in this biotite specimen: highly altered laths that are largely amorphous but that still contain wisps of remnant layering and copper-rich inclusions that look similar to the native copper inclusions but that rapidly evaporate under the condensed electron beam. The inclusions are associated with the remnant layering. Due to the ephemeral nature of these inclusions we have not identified them yet. Areas with remnant layering and copper-rich inclusions contain more copper and higher Al/Si ratios than partially vermiculitized areas such as that shown in Figure 29. Amorphous areas (zones without observable layering) contain the highest $\mathrm{Al} / \mathrm{Si}$ ratios, negligible $\mathrm{Mg}, \mathrm{Fe}$, and $\mathrm{K}$, and relatively low copper concentrations. AEM analyses of amorphous laths plot towards the lower right-hand side of Figure 28b. Another feature of the zones illustrated in Figure 30 is that they contain numerous holes that commonly bear striking resemblance in outline to the copper inclusions. Note how the remnant layering tends to deflect around the holes. The inset in Figure 30 is an SAED pattern of the area; the bright spots correspond to the $10-\AA$ layer-repeat of biotite, and the arrowed spots correspond to the $14-\AA$ layer-repeat of the remnant layering. The arcuate pattern of the $14-\AA$ spots reflects the morphology of the remnant layering that has been deflected around the holes.

The highest copper concentrations are associated with domains that contain tightly interspersed narrow laths of amorphous and 14- $\AA$ layered phases. A high density of copperrich inclusions lies along the borders of the amorphous and layered laths, as well as in remnant 
layering in the amorphous lathes. These inclusions also evaporate under the condensed electron beam. AEM analyses of these areas plot in the upper portion of Figure 28b.

AEM analyses of well-ordered, inclusion-free chlorite show 1.5 to 4.4 normative wt.\% CuO. We suggest that copper is incorporated in the brucite-like sheet. We emphasize that the chlorites did not become copper-rich during the hydrothermal-magmatic event. In other areas, chlorites are disrupted, and they are associated with amorphous zones and the mysterious evaporating copper-rich inclusions. These areas have similar compositions to the high-copper zones described for biotite. It is possible that these zones were once laths of biotite intergrown with chlorite. Alternatively, biotite and chlorite might have been altered to similar secondary products. AEM analyses for chlorite are plotted in Figure 28c.

The following was reported in our 1991 progress report; it is included in order to facilitate the discussion- The high values of copper concentrations in biotites that were not intimately intergrown with sulfides are primarily a function of intergrowths of an amorphous aluminosilicate phase, which appears to have forced the biotite layers apart (Fig. 18 in our Progress report for 1991). Other than these intergrowths, the biotites appear relatively unweathered; both expanded interlayers in biotite and associated native copper inclusions are rare or absent. The intergrowths range from 10 to $500 \mathrm{~nm}$ thick and contain numerous copperand iron-rich inclusions. Other than the high concentrations of copper and iron, these amorphous zones have similar compositions to those of the amorphous zones described previously. Although the $\mathrm{Al} / \mathrm{Si}$ phase is amorphous, the array of inclusions displays a lineation. This may indicate that the amorphous phase was layered at some time in its history. The density of inclusions precludes a clean analysis of an inclusion-free area. Therefore, we cannot determine with any certainty the percentage of copper and iron in the amorphous phase not contributed by the inclusions. The iron-rich inclusions appear to contain substantial concentrations of copper, whereas the copper inclusions appear to be relatively pure, with little or no iron. The high density of inclusions makes it difficult to obtain clean analyses of the inclusions (i.e., they even can overlie each other), and the inclusions have not been positively 


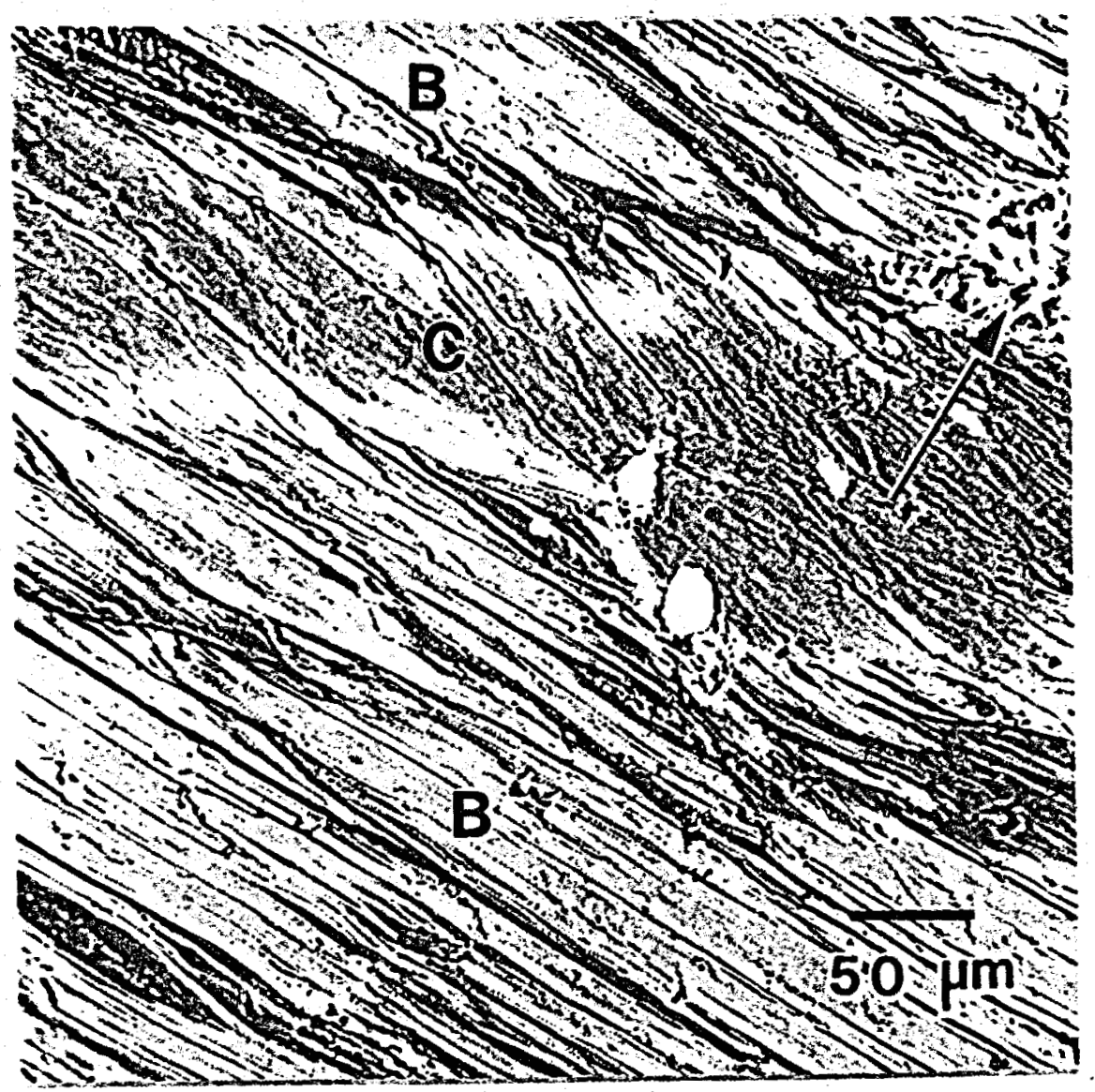

Fig. 27: SEM backscatter electron photomicrograph of biotite from the chrysocolla zone of the Cyprus Casa Grande porphyry copper deposit. A chlorite vein that bisects biotite is labeled C; biotite is labeled B. A clot of chrysocolla with intergrown iron oxide/hydroxide is arrowed. The bright inclusions are titanium oxides. 

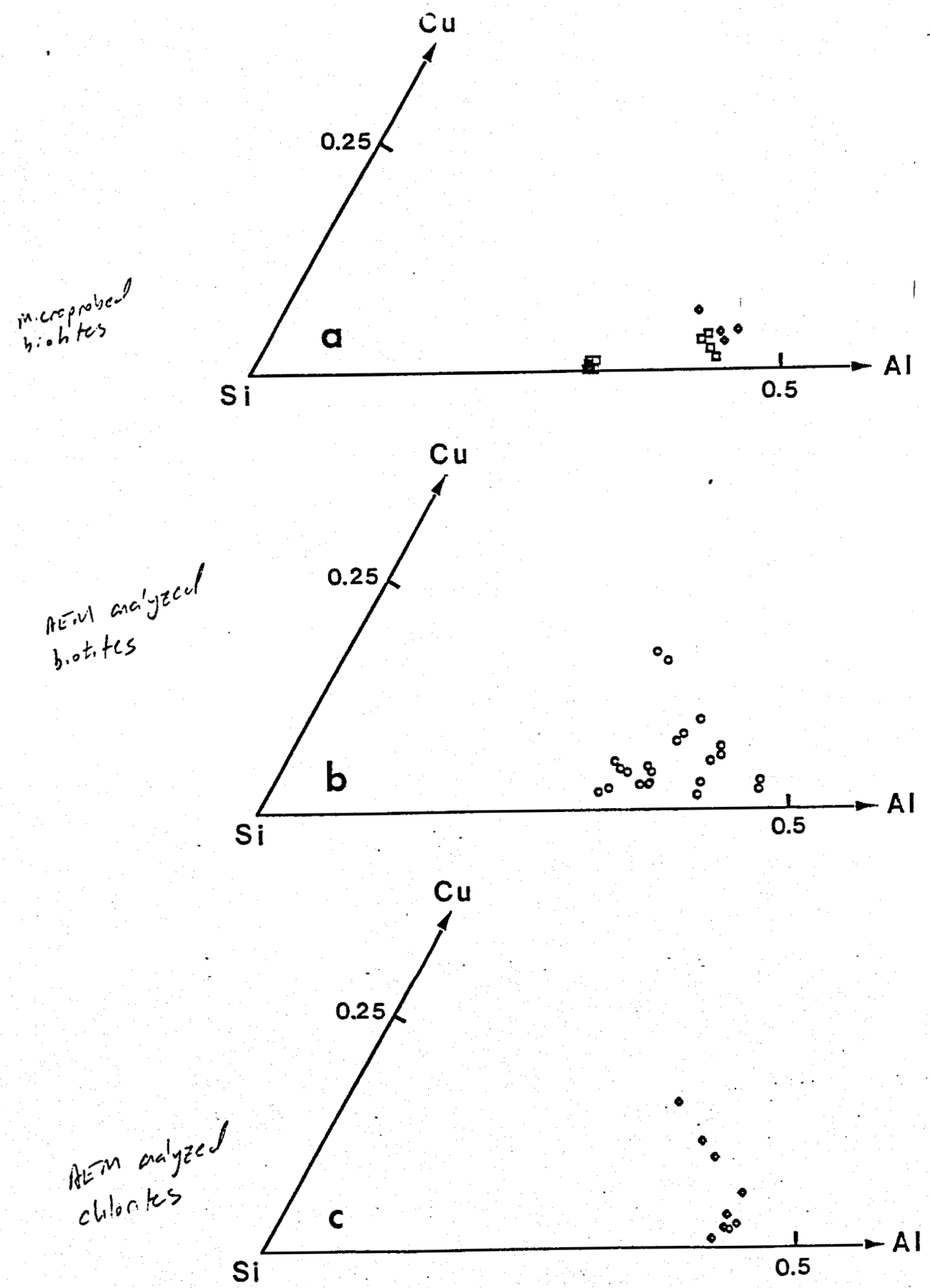

Fig. 28: Relative atomic proportions of $\mathrm{Cu}, \mathrm{Si}$, and $\mathrm{Al}$ in one biotite grain from the chrysocolla zone. The analyses come from the general area shown in figure 4. (a) Electron microprobe analyses of biotite and clay intergrowths in biotite (squares), and chlorite and clay intergrowths in chlorite (diamonds). (b) AEM analyses of biotite and alteration products of biotite. (c) AEM analyses of chlorite and alteration products of chlorite. 


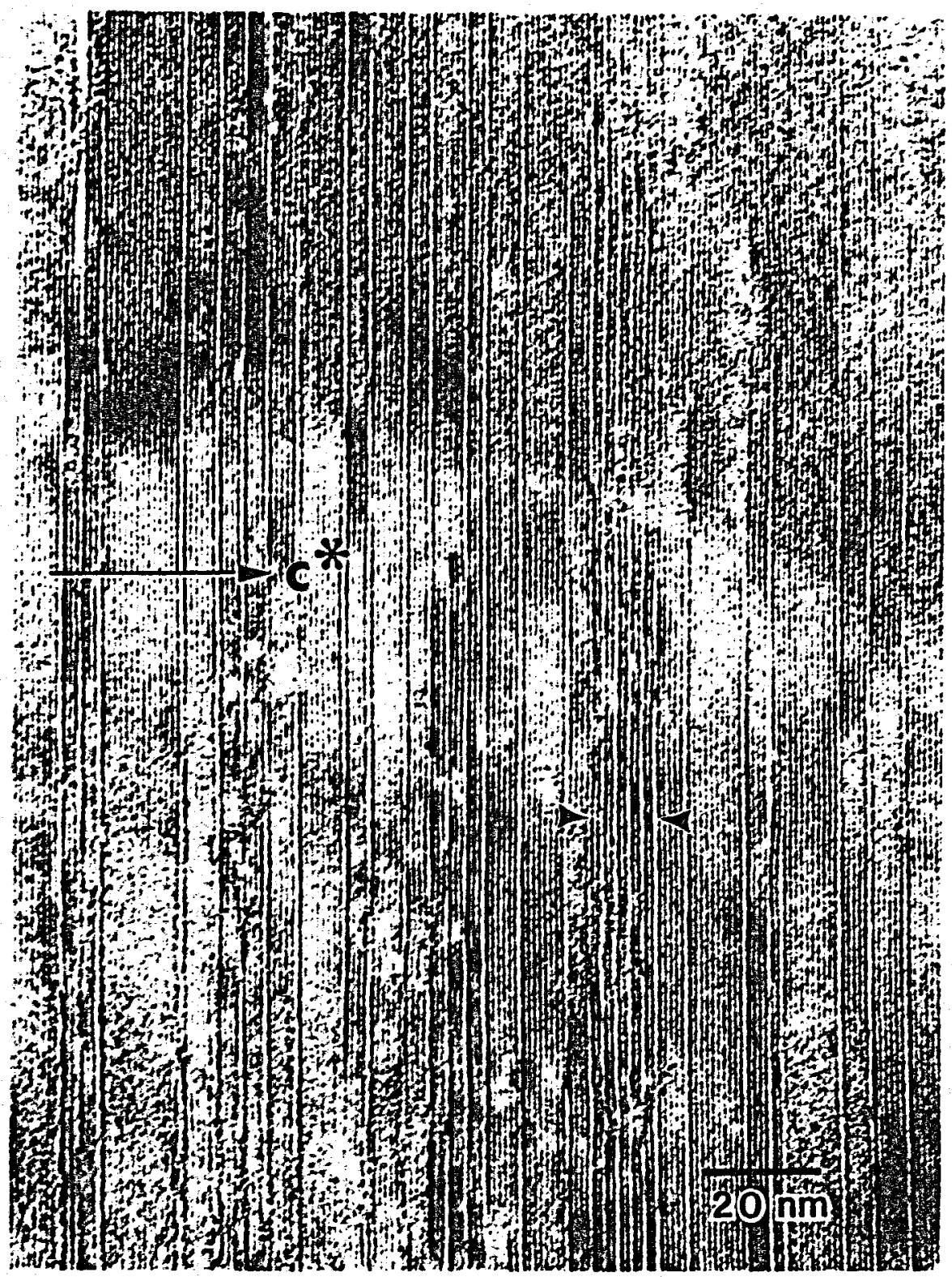

Fig. 29: HRTEM image of biotite from the chrysocolla zone of the Cyprus Casa Grande porphyry copper deposit. The layers with lighter contrast are expanded interlayers. Areas of biotite with this density of expanded interlayers commonly contain up to $\sim 3.5$ normative wt.\% $\mathrm{CuO}$ by AEM. The region between the arrows shows alternating biotite and vermiculite-like layers. 


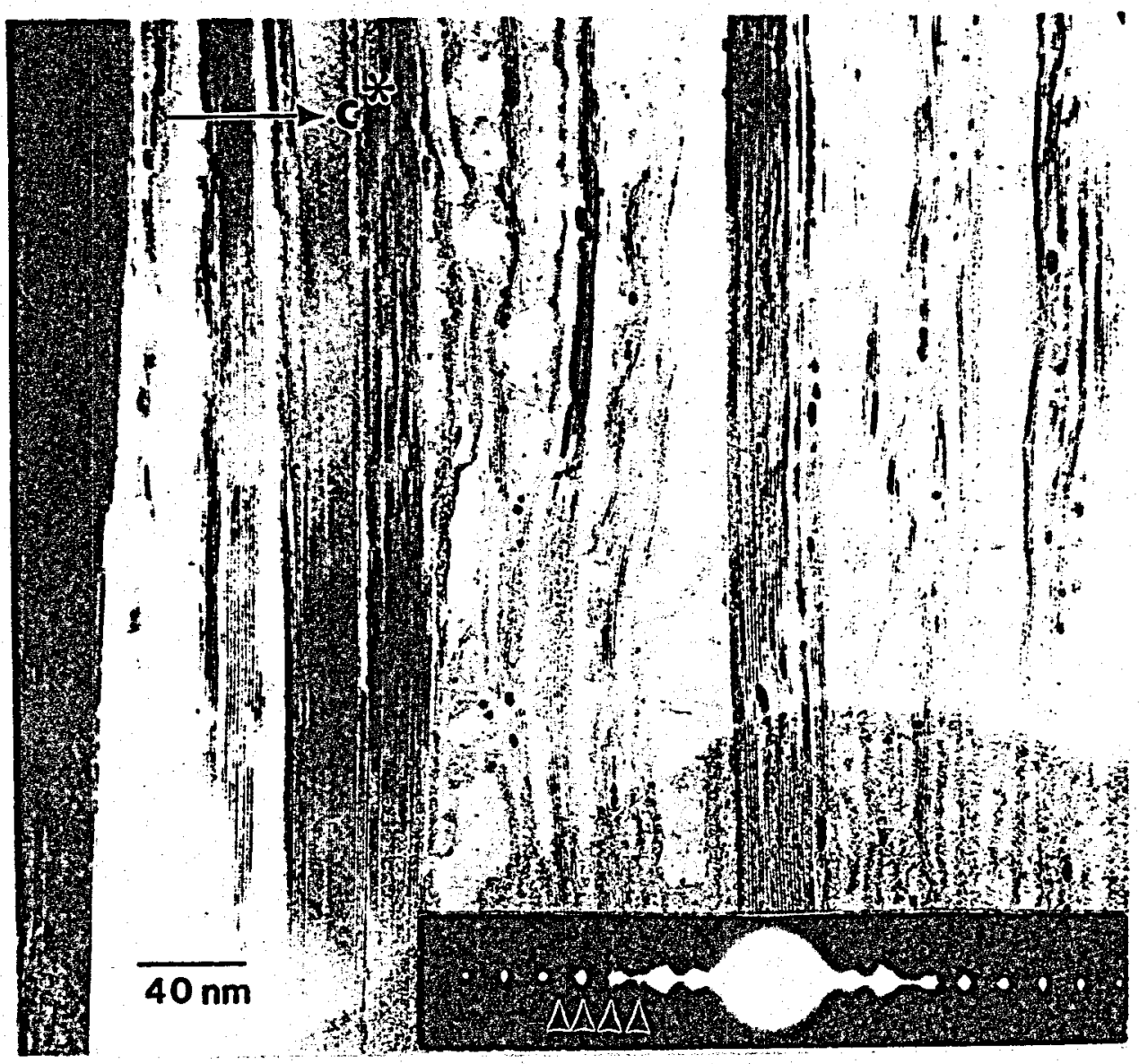

Fig. 30: TEM image of biotite from the chrysocolla zone of the Cyprus Casa Grande porphyry copper deposit. The image shows relatively unaltered biotite (dark laths) juxtaposed with highly altered biotite domains that are largely amorphous but still contain wisps of layering. The numerous inclusions are copper-rich and evaporate rapidly under the condensed electron beam. These inclusions have not been identified. Note the numerous holes, some of which resemble in outline native copper inclusions. Note also how the remnant layering wraps around some of the holes. The inset is an SAED pattern of the general area. The bright reflections give the $10-\AA$ spacing of biotite; the arrowed arcuate reflections yield $14-\AA$ spacing. The $14-\AA$ spacing corresponds to the remnant layering; the arcuate shapes of the $14-\AA$ spots reflect the morphology of the remnant layering that has been deflected around the holes 
identified yet. The copper-rich inclusions are, however, stable under the condensed electron beam, which is consistent with the behavior of native copper.

Discussion - The occurrence of copper-rich inclusions that evaporate under the condensed electron beam and that are associated with alteration zones such as that shown in Figure 30 was described in detail previously. We suggest that these domains were once sites of intense native copper inclusion deposition but that after the deposition event both the host sheet silicate and copper inclusions started to dissolve. Continued dissolution produced the amorphous zones with low copper. We interpret the holes to record the former location of native copper inclusions that have dissolved. The unstable inclusions might once have been native copper inclusions that are now hydrated and were caught in the act of dissolution.

Cook (1988) interpreted the compositional trends in altered biotite (Fig. 6c, Cook, 1988) to indicate that copper was substituting for aluminum. We suggest that this correlation is coincidental; TEM observations indicate that decreasing copper with increasing $\mathrm{Al} / \mathrm{Si}$ ratios is correlated to decreasing interlayer sites (i.e., increased amorphous areas) and decreasing numbers of copper-rich inclusions.

\section{FUTURE WORK}

The long term goals of this project have not changed from those in our grant proposal. Instead, we discuss some shorter-term goals and priorities with respect to the experimental work and the natural samples. Because XPS has proven a most useful tool for this project, we intend to continue using XPS during the course of this project.

\section{EXPERIMENTS}

We have completed a number of reconnaissance experiments which need to be fine tuned and extended. We have not done any experiments on $\mathrm{Cd}$. Therefore, an obvious 
priority is to start the cadmium experiments. The following is a compilation of some other priorities.

\section{Silver}

Lower $\mathrm{Ag}$ concentrations in solution need to be explored to better simulate natural conditions. We need quantitative electron microprobe analyses and $\mathrm{X}$-ray maps ( $\mathrm{Ag}$ and $\mathrm{K}$ ) of reacted biotite flakes in order to understand more fully the reactions associated with $\mathrm{Ag}$ sorption (like we have for $\mathrm{Cu}$ ). We also need to obtain TEM images of reacted biotite parallel to the sheets.

\section{Selenium}

Our first task is to keep the extraction procedure anoxic. This can be accomplished by extracting the biotite in a nitrogen-purged glove box, and then rinsing the flakes in anoxic water. We will transfer the dried biotite flakes to an environmental chamber that has been placed the glove box. The chamber is sealed and the biotite samples can then be transferred to the ESCA 300 (the XPS machine) without exposure to oxygen.

We also intend to start anoxic experiments. The biotite grains will be transferred to the ESCA 300 as described above. Moreover, we will use lower and lower concentrations of Se.

\section{Chromium}

We intend to react identical solutions of hexavalent chromium with biotite and pure endmember fluorophlogopite in order to test whether or not biotite is indeed reducing the chromium. We will also use variable concentrations of anions (such as phosphate) to block edge sites in order to help elucidate whether or not the $\mathrm{Cr}^{6+}$-oxyanion is adsorbed and reduced at edge sites. We need to make TEM observations of the reacted micas. 


\section{NATURAL SAMPLES}

We have laid the biotites to rest. Our focus from now on will be on the feldspars and vein assemblages from the Cyprus Casa Grande porphyry copper deposit. We have already made appreciable progress with respect to plagioclase. One priority will be to document the sequence of alteration reactions that lead to the enrichment of copper.in plagioclase by studying representative plagioclase phenocrysts from the protore and from all of the major oxidized zones. Plagioclase grains from the protore, chrysocolla, and goethite zone will be examined first by EMP, and then by TEM/AEM.

\section{REFERENCES}

Cook, S. S., 1988, Supergene copper mineralization at the Lakeshore Mine, Pinal County, Arizona: Economic Geology, v. 83, p. 297-309.

Bancroft, G.M., and Hyland, M.M., 1990, Spectroscopic studies of adsorption/reduction reactions of aqueous metal complexes on sulphide surfaces, In Reviews in Mineralogy, V. 23, Mineral-Water Interface Geochemistry, Hochella, M.F., and White, A.F. (eds.):. Mineralogical Society of America, Washington D.C., p. 511-558.

Earley III, D., Ilton, E.S., and Veblen, D.R.,1991, Cu uptake by high- and low-F biotites during experimental weathering of biotite with $\mathrm{CuSO}_{4}$ solutions: Geol. Soc. Amer. Abstracts with Program 23, p. 152.

Fanning, D.S., and Keramidas, V.Z., 1977, Micas, in Dixon, J.B. and Weed, S.B. (eds), Minerals in Soil Environments: Soil Science Society of America, Madison, Wisconsin, p. $195-241$.

Hering, J.G., and Stumm, W., 1990, Oxidation and Reductive Dissolution of Minerals, In Reviews in Mineralogy, V. 23, Mineral-Water Interface Geochemistry, Hochella, M.F., and White, A.F. (eds.):. Mineralogical Society of America, Washington D.C., p. 427466. 
Hoda, S.N., and Hood, W.C., 1972, Laboratory alteration of trioctahedral micas: Clays and Clay Minerals, v. 20, p. 343-358.

Ilton, E. S., and Veblen, D. R.,1988, Copper inclusions in sheet silicates from porphyry deposits: Nature, v. 334, p. 516-518.

Ilton, E.S., Earley, D., Morozas, D., and Veblen, D.R., In Press, Reaction of some trioctahedral micas with copper sulfate solutions at $25^{\circ} \mathrm{C}$ and 1 atmosphere: Electron microprobe and TEM observations: Economic Geology

Ilton, E.S. and Veblen D.R., In Review, The origin and mode of $\mathrm{Cu}$ enrichment in biotites from porphyry Cu environments: A TEM study. Submitted to Economic Geology.

White, A.F., and Yee, A., 1985, Aqueous oxidation-reduction kinetics associated with coupled electron-cation transfer from iron-containing silicates at $25^{\circ} \mathrm{C}$ : Geochim. et Cosmochim. Acta, v. 49, p. 1263-1275.

White, A.F., 1990, Heterogeneous electrochemical reactions associated with oxidation of ferrous oxide and silicate surfaces, In Reviews in Mineralogy, V. 23, Mineral-Water Interface Geochemistry, Hochella, M.F., and White, A.F. (eds.):. Mineralogical Society of America, Washington D.C., p. 467-510. 


\section{APPENDIX I: RELEVANT PUBLICATIONS FOR 1991-1992}

Ilton, E.S., Earley, D., Morozas, D., and Veblen, D.R. (In Press) Reaction of some trioctahedral micas with copper sulfate solutions at $25^{\circ} \mathrm{C}$ and 1 atmosphere: Electron microprobe and TEM observations. Economic Geology

Ilton, E.S. and Veblen D.R. (In Review) The origin and mode of $\mathrm{Cu}$ enrichment in biotites from porphyry Cu environments: A TEM study. Submitted to Economic Geology.

Veblen, D.R. and Ilton, E.S. (1991) Applications of transmission electron microscopy (TEM) in economic geology. Geol. Soc. Amer. Abstracts with Program 23, 100.

Earley III, D., Ilton, E.S. and Veblen, D.R. (1991) Cu uptake by high- and low-F biotites during experimental weathering of biotite with $\mathrm{CuSO}_{4}$ solutions. Geol. Soc. Amer. Abstracts with Program 23, 152. 